\title{
Diabetes and pancreatic cancer
}

\author{
YunFeng $\mathrm{Cui}^{1,2 *}$ and Dana K Andersen ${ }^{1 *}$
}

Department of Surgery, Johns Hopkins Bayview Medical Center, Johns Hopkins University School of Medicine, Baltimore, Maryland, USA

${ }^{1}$ Department of Surgery, Nankai Clinical School of Medicine, Tianjin Nankai Hospital, Tianjin Medical University, Tianjin, China

(Correspondence should be addressed to D K Andersen who is now at Division of Digestive Diseases and Nutrition, National Institute of Diabetes and Digestive and Kidney Diseases, National Institutes of Health, Building DEM2, Room 659, 6707 Democracy Boulevard, Bethesda, Maryland 20892, USA; Email: andersendk@niddk.nih.gov)

*(Y Cui and D K Andersen contributed equally to this work)

\begin{abstract}
Epidemiological studies clearly indicate that the risk of pancreatic cancer (PC) is increased in diabetic patients, but most studies focus on overall diabetes or type 2 diabetes mellitus (T2DM), and there are few studies on the risks of type 1 and type 3c (secondary) diabetes. Possible mechanisms for increased cancer risk in diabetes include cellular proliferative effects of hyperglycemia, hyperinsulinemia, and abnormalities in insulin/IGF receptor pathways. Recently, insulin and insulin secretagogues have been observed to increase the PC risk, while metformin treatment reduces the cancer risk in diabetic subjects. In addition, anticancer drugs used to treat PC may either cause diabetes or worsen coexisting diabetes. T3cDM has emerged as a major subset of diabetes and may have the highest risk of pancreatic carcinoma especially in patients with chronic pancreatitis. T3cDM is also a consequence of PC in at least $30 \%$ of patients. Distinguishing T3cDM from the more prevalent T2DM among new-onset diabetic patients can be aided by an assessment of clinical features and confirmed by finding a deficiency in postprandial pancreatic polypeptide release. In conclusion, diabetes and PC have a complex relationship that requires more clinical attention. The risk of developing $\mathrm{PC}$ can be reduced by aggressive prevention and treatment of T2DM and obesity and the prompt diagnosis of T3cDM may allow detection of a tumor at a potentially curable stage.
\end{abstract}

Endocrine-Related Cancer (2012) 19 F9-F26

\section{Introduction}

Pancreatic cancer (PC) is one of the most lethal malignant diseases due to the high rate of advanced stage disease at diagnosis and the lack of any effective medical therapy (Ko \& Tempero 2009). The overall incidence of the disease has increased over the past few decades such that over 265000 people worldwide are diagnosed annually (Jemal et al. 2011). Five-year survival after surgical resection has slowly risen to about $20 \%$, owing to better selection of surgical candidates and some modest improvements in adjuvant therapy, but only $10-15 \%$ of patients are candidates for resection, and more than $95 \%$ of all patients will succumb to their illness within 2 years of diagnosis (Edwards et al. 2005). This high mortality rate confers $\mathrm{PC}$ as the fourth leading cause of cancer-related deaths in the USA currently (Jemal et al. 2010). With the continuing decline in mortality rates of cancers of the lung, colon, breast, and prostate due to the combined effects of widespread screening, smoking cessation, and more effective therapy, it is projected that pancreas cancer will become the leading cause of cancer-related deaths in the USA by 2050 (Siegel et al. 2012).

The etiology of PC is complex and poorly understood. Therefore, the identification of risk factors, especially those that are modifiable through medication or behavioral change, is important for preventing the development and progression of PC. Risk factors for PC include family history, smoking, obesity, chronic pancreatitis (CP), and diabetes mellitus (DM). The recent increase in the prevalence of type $2 \mathrm{DM}$ (T2DM) is thought to have contributed to a parallel rise in the incidence of PC. Roughly half of all PC patients are found to have DM at the time of diagnosis, and roughly half of the DM that is present at the time of $\mathrm{PC}$ diagnosis is of new onset having developed over 
2-3 years preceding the diagnosis of PC. This newonset DM is therefore thought to be secondary, or $\mathrm{T} 3 \mathrm{cDM}$. The association between PC and DM has been investigated extensively, but the causal relationships have yet to be fully elucidated, in part due to difficulties in distinguishing T2DM from T3cDM.

In this review, we highlight the important recent studies and discuss the available evidence concerning the possible mechanisms that are involved in the etiological role of DM in the development of PC, the effects of antidiabetic therapy on the risk of PC, and a strategy for distinguishing T3cDM from T2DM so as to identify the patient with early and indolent PC.

\section{Diabetes (and obesity) as a cause of PC}

\section{The risk of PC is increased in T1DM, T2DM, and T3cDM}

It has long been known that PC is associated with DM, and recent studies have revealed that about $85 \%$ of patients diagnosed with PC have impaired glucose tolerance or frank DM (Pannala et al. 2008; Fig. 1). $\mathrm{DM}$ is a group of metabolic disorders characterized by hyperglycemia. The three most common subtypes of DM differ greatly in their metabolic and hormonal characteristics, however (Table 1; Cui \& Andersen 2011). T1DM is associated with a profound or absolute deficiency of endogenous insulin secretion and an absolute requirement for exogenous insulin administration. Hyperglycemia and hyperinsulinemia coexist in T2DM due to insulin resistance in peripheral tissues usually in association with obesity. T3cDM is associated with benign and malignant disease of the exocrine pancreas, including acute and $\mathrm{CP}$ of any etiology, pancreatic neoplasms, pancreatic trauma, pancreatic resection, cystic fibrosis, hemochromatosis, fibrocalculous pancreatopathy, and pancreatic agenesis and is characterized by a severe deficiency of all pancreatic glucoregulatory hormones (American Diabetes Association 2011, Cui \& Andersen 2011).

Epidemiological studies have demonstrated that DM is a risk factor for multiple forms of malignancy including PC (Wideroff et al. 1997, Calle et al. 2003, Huxley et al. 2005). A recent meta-analysis of 35 cohort studies concluded that a twofold risk of pancreatic malignancy exists in diabetic patients (Ben et al. 2011). DM was associated with an increased relative risk $(\mathrm{RR})$ of $\mathrm{PC}(\mathrm{RR}=1.94 ; 95 \%$ confidence interval (95\% CI): 1.66-2.27), with significant evidence of heterogeneity among the studies surveyed $\left(P<0.001, I^{2}=93.6 \%\right)$. Subgroup analyses revealed that the increased risk of PC was independent of geographic location, sex, study design, alcohol consumption, body mass index (BMI), and/or smoking status. In addition, the risk of PC correlated negatively with the duration of DM, with the highest risk of PC found among patients with DM diagnosed within $<1$ year. This finding implies that many of the diabetic subjects had PC-induced DM (T3cDM), but the type of DM was not identified in most epidemiological studies.

A meta-analysis of three recent studies in which 2192 PC patients were compared with 5113 controls revealed a 1.8 -fold increase in risk of PC associated with T2DM, although many of the patients classified as
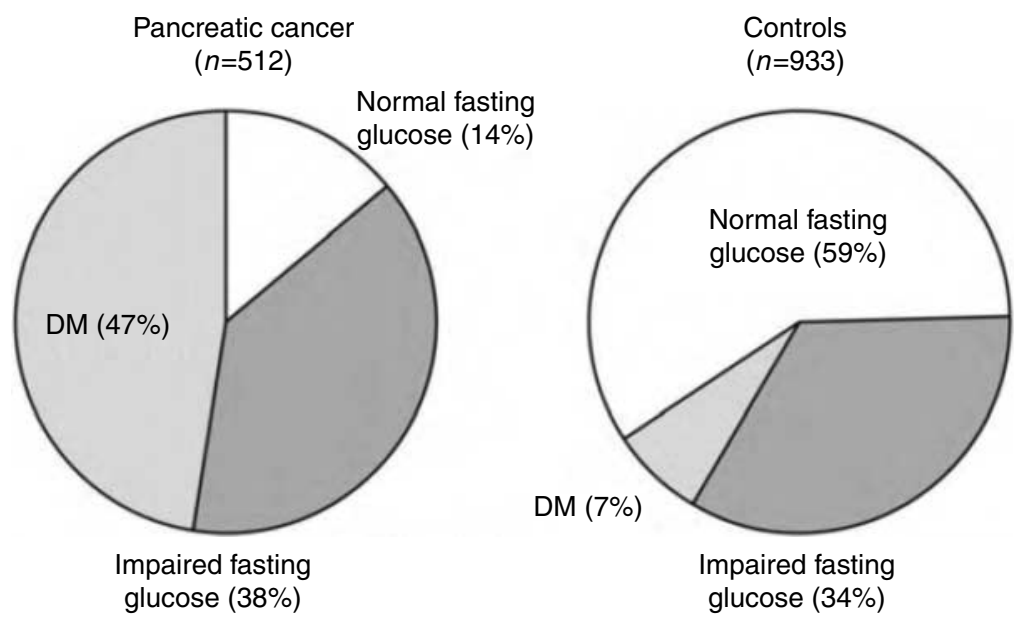

Figure 1 Distribution of fasting blood glucose among pancreatic cancer cases and controls. Normal fasting glucose, $\leq 99 \mathrm{mg} / \mathrm{dl}$; impaired fasting glucose, 100-125 mg/dl; diabetes (DM), $\geq 126 \mathrm{mg} / \mathrm{dl}$. Reproduced, with permission, from Pannala R, Leirness JB, Bamlet WR, Basu A, Petersen GM \& Chari ST 2008 Prevalence and clinical profile of pancreatic cancer-associated diabetes mellitus. Gastroenterology 134 981-987. Copyright 2008 AGA Institute. 
Table 1 Clinical and laboratory findings in types of diabetes mellitus

\begin{tabular}{|c|c|c|c|}
\hline Parameter & $\begin{array}{l}\text { Type } 1 \\
\text { IDDM }\end{array}$ & $\begin{array}{l}\text { Type } 2 \\
\text { NIDDM }\end{array}$ & $\begin{array}{l}\text { Type 3c } \\
\text { Pancreatogenic }\end{array}$ \\
\hline Ketoacidosis & Common & Rare & Rare \\
\hline Hyperglycemia & Severe & Usually mild & Mild \\
\hline Hypoglycemia & Common & Rare & Common \\
\hline $\begin{array}{l}\text { Peripheral } \\
\text { insulin } \\
\text { sensitivity }\end{array}$ & $\begin{array}{l}\text { Normal or } \\
\text { increased }\end{array}$ & Decreased & Increased \\
\hline $\begin{array}{l}\text { Hepatic insulin } \\
\text { sensitivity }\end{array}$ & Normal & $\begin{array}{l}\text { Normal or } \\
\text { decreased }\end{array}$ & Decreased \\
\hline Insulin levels & Low & High & Low \\
\hline Glucagon levels & $\begin{array}{l}\text { Normal } \\
\quad \text { or high }\end{array}$ & $\begin{array}{l}\text { Normal or } \\
\text { high }\end{array}$ & Low \\
\hline PP levels & $\begin{array}{l}\text { Normal or } \\
\text { low (late) }\end{array}$ & High & Low \\
\hline GIP levels & $\begin{array}{l}\text { Normal or } \\
\text { low }\end{array}$ & Normal & Low \\
\hline GLP1 levels & Normal & $\begin{array}{l}\text { Normal or } \\
\text { low }\end{array}$ & $\begin{array}{l}\text { Normal } \\
\quad \text { or high }\end{array}$ \\
\hline $\begin{array}{l}\text { Typical age of } \\
\text { onset }\end{array}$ & $\begin{array}{c}\text { Childhood } \\
\text { or ado- } \\
\text { lescence }\end{array}$ & Adulthood & Any \\
\hline
\end{tabular}

IDDM, insulin-dependent diabetes mellitus; NIDDM, noninsulin-dependent diabetes mellitus; PP, pancreatic polypeptide; GIP, glucose-dependent insulinotropic polypeptide; GLP1, glucagon-like peptide 1. Modified, with permission, from Slezak LA \& Andersen DK 2001 Pancreatic resection: effects on glucose metabolism. World Journal of Surgery 25 452-460.

Copyright 2001 International Society of Surgery.

T2DM likely harbored T3cDM, which became evident close to the time of diagnosis of the cancer ( $\mathrm{Li}$ et al. 2011). Finally, a recent cohort study comparing 110919 DM subjects and 211695 controls provides strong support for an etiological role of T2DM and hyperinsulinemia in the pathogenesis of PC (Yacoub et al. 2011). The DM cohort had 124 PCs developed during 0.558 million person-years (MPY) of follow-up (222 PCs/MPY), whereas the control cohort had 140 PCs developed during 1.299 MPY of follow-up (108 PCs/MPY). Stratified Cox regression of PC incidence yielded a hazard ratio (HR) of 2.17 (95\% CI: 1.70-2.77) for T2DM compared to controls. So the risk of developing PC is clearly although modestly increased (about twofold) in the presence of longstanding, mostly T2DM.

Genetic studies have also provided insights underlying the association of DM and PC. Pierce et al. (2011) examined the 37 risk alleles of T2DM and found two that showed nominally significant positive associations with PC risk (FTO rs8050136 per allele odds ratio $(\mathrm{OR})=1.12 ; 95 \% \mathrm{CI}: 1.02-1.23$; MTNR1B rs 1387153 OR $=1.11 ; 95 \%$ CI: $1.00-1.23$ ), and the glucose-raising allele of MADD rs11039149 was associated with increased risk of $\mathrm{PC}(\mathrm{OR}=1.14$; 95\% CI: 1.03-1.27). Prizment et al. reported that glucokinase regulator (GCKR) rs780094, a singlenucleotide polymorphism related to T2DM, may be associated with PC risk. In a multivariate-adjusted model, a significant association was observed only for rs780094 in the GCKR gene: ORs for PC were 1.00 for the TT genotype, 1.35 (95\% CI: 0.71-2.58) for the CT genotype, and 2.14 (95\% CI: 1.12-4.08) for the CC genotype $(P=0.01)$, which did not change after the adjustment for the presence of DM (Prizment et al. 2012).

There are few studies that specifically address cancer incidence in T1DM patients. A cohort study evaluating cancer incidence in nearly 30000 Swedish T1DM patients diagnosed in the period 1965-1999 identified 355 cases of cancer, which equated to a standardized incidence ratio of 1.2 (95\% CI: $1.0-1.30)$ compared with the general Swedish population (Zendehdel et al. 2003). In contrast to these modest findings, a meta-analysis including three cohort studies and six case-control studies has found that the RR for PC was doubled in T1DM patients and 'young-onset' diabetics in comparison with nondiabetics (Stevens et al. 2007).

T3cDM has emerged as a major subset of the total population of DM and harbors the highest risk of PC especially in patients with $\mathrm{T} 3 \mathrm{cDM}$ secondary to $\mathrm{CP}$ (Cui \& Andersen 2011). Persons with any form of CP are at increased risk of developing PC, and Lowenfels et al. (1993) observed that the risk is cumulative over the course of CP, such that $4-5 \%$ of patients develop PC over the course of 20 years, a risk that is 10-20 times greater than the general population. In a casecontrol study in which 823 PC patients and 1679 controls were surveyed from centers in Australia, Canada, The Netherlands, and Poland, the risk of PC was seen to be increased (RR 4.7) for subjects with a history of pancreatitis (not otherwise defined), although was increased only among alcohol drinkers (RR 7.5) and not among teetotalers (RR 0.57; Maisonneuve et al. 2010; Fig. 2). A recent cohort study in Taiwan showed that in addition to age, CP $(\mathrm{HR}=19.40)$, gallstones $(\mathrm{HR}=2.56)$, and hepatitis $\mathrm{C}$ infection $(\mathrm{HR}=3.08)$ were significant factors predicting PC; patients with concurrent DM and $\mathrm{CP}$ had a dramatically elevated risk of developing PC $(\mathrm{HR}=33.52)$, compared with subjects without these comorbidities (Liao et al. 2012).

\section{Obesity as a risk factor for PC}

In 2003, Calle et al. (2003) examined the American Cancer Society database to assess the possible role of 
(a)

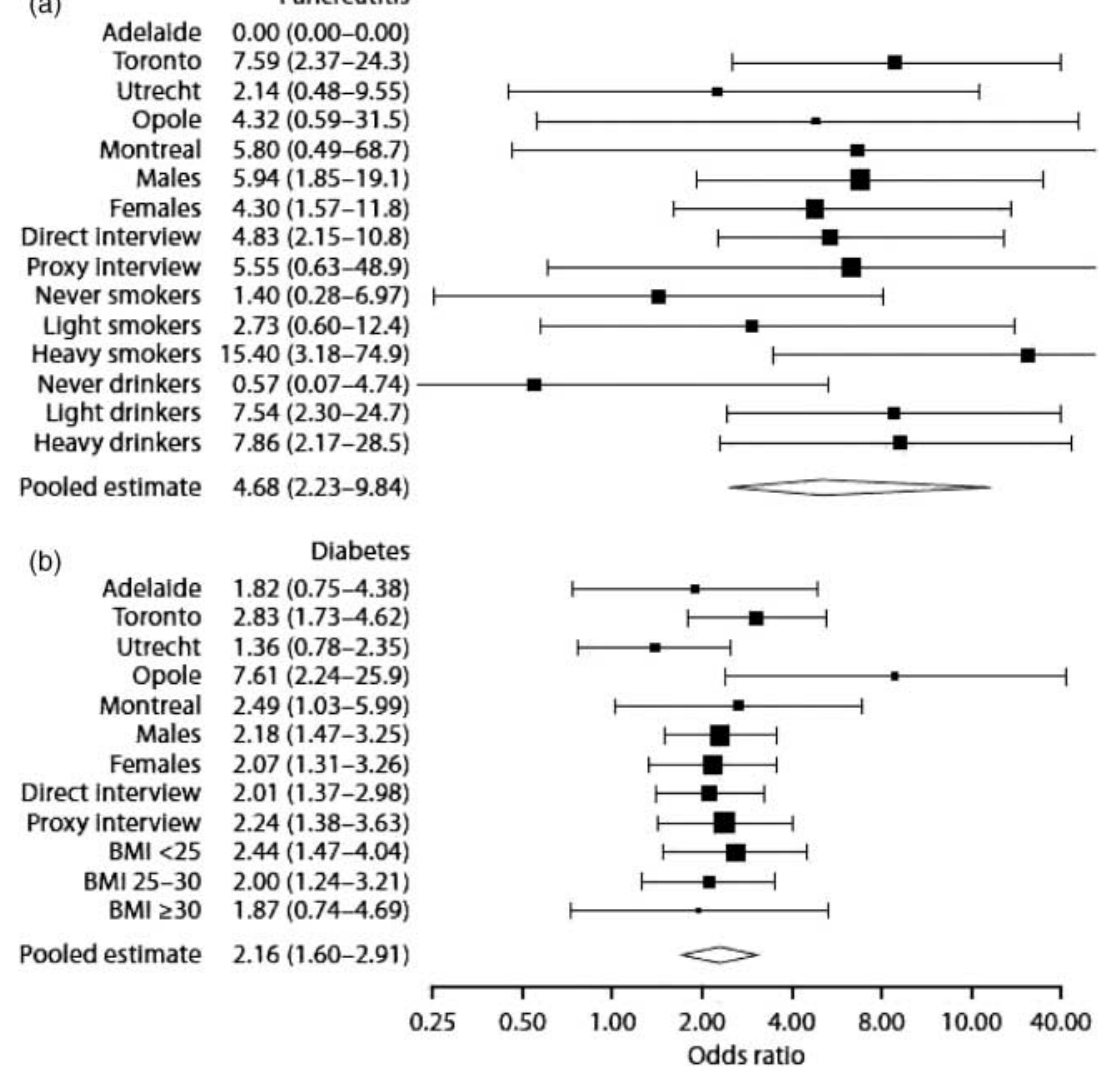

Figure 2 Risk of pancreatic cancer based on the history of pancreatitis or diabetes. The odds ratio of subsequent pancreatic cancer based on the medical history of pancreatitis (upper panel) or diabetes (lower panel) in 823 patients with pancreatic cancer and 1679 controls surveyed in Australia (Adelaide), Canada (Toronto and Montreal), The Netherlands (Utrecht), and Poland (Opole).

Reproduced, with permission, from Maisonneuve P, Lowenfels AB, Bueno-de-Mesquita HB, Ghadirian P, Baghurst PA, Zatonski WA, Miller AB, Duell EJ, Boffetta P \& Boyle P 2010 Past medical history and pancreatic cancer risk: results from a multicenter case-control study. Annals of Epidemiology 20 92-98. Copyright 2010 Elsevier Inc.

obesity on the risk of cancer. In their cohort of over 900000 individuals, massive obesity (BMI > 40) was associated with a $50-60 \%$ increased death rate from cancers of the pancreas, liver, kidney, colon and rectum, esophagus, non-Hodgkins lymphoma, and multiple myeloma over a 16-year period. The greatest effects were seen in liver cancer (RR 4.52 for men and 1.68 for women), colorectal cancer (RR 1.84 for men and 1.46 for women), and PC (RR 1.49 for men and 2.76 for women). Over $80 \%$ of T2DM patients are obese and studies on the obesity-PC association are influenced by the high prevalence of obesity in T2DM patients and by the high percentage of T2DM that is undiagnosed. Recent epidemiological studies have demonstrated that a high BMI is positively associated with an increased risk of many common cancers independent of the coexistence of T2DM (Teucher et al. 2010), and a high BMI has been identified as an independent risk factor for PC (Michaud et al. 2001, Silverman 2001, Gumbs 2008, Arslan et al. 2010).
More recently, large prospective cohort studies with a long duration of follow-up have been conducted in the USA showing a positive association between high BMI and the risk of PC (adjusted RR 1.13-1.54; Jiao et al. 2010, Johansen et al. 2010), suggesting the role of obesity and overweight as conferring a higher risk for the development and eventual death due to PC. Among the many possible mechanisms involved, hyperinsulinemia, diet and nutritional factors, and other hormone abnormalities have been suggested as causal factors.

Reduced caloric intake and physical exercise have both been shown to reduce the risk of PC (Michaud et al. 2001, Silverman 2001), and studies on the effects of bariatric surgery are also consistent with a reduction in PC risk after weight loss. In 2007, the Swedish Bariatric Surgery Trial reported a $38 \%$ reduction in cancer-related deaths compared with nonoperated controls of similar BMI (Sjöström et al. 2007), and a significant reduction in cancer-related medical care was documented in a study of 1035 bariatric surgery 
patients compared to 5746 morbidly obese controls reported by Christou et al. (2008). In a similar but larger study, Adams et al. (2009) found a lower incidence of obesity-related cancers, defined as esophageal, colorectal, pancreas, liver, gallbladder, breast, and uterine cancers, in addition to nonHodgkin's lymphoma, leukemia, and multiple myeloma in 6596 gastric bypass patients compared with 9442 morbidly obese control subjects. As with the studies by Sjöström et al. and Christou et al., the incidence of PC, per se, was too low for valid statistical analysis. Although the mechanisms of risk-reduction remain speculative, the successful treatment of morbid obesity (and concomitant T2DM in about half the subjects) appears to clearly reduce the risk of malignancy and may reduce the incidence of PC.

\section{Proliferation rates of pancreatic ductal endo- thelium in diabetes and obesity}

The effects of DM and obesity on pancreatic ductal pathology were recently studied by Butler et al. (2010), who examined the expression of the neoplastic markers cytokeratin and Ki67 in pancreatic ductal epithelia from 45 human autopsy and nine surgical pathology specimens. In autopsy specimens obtained from obese nondiabetic individuals, pancreatic duct replication was seen to be increased tenfold compared with lean nondiabetics. In lean diabetics, duct epithelial replication was increased fourfold compared with lean nondiabetic subjects. These results indicate the independent effects of obesity and long-standing diabetes on the replication rate in pancreatic ductal cells and presumably therefore on the likelihood of the development of pancreatic exocrine neoplasia (Fig. 3). Markers of pancreatic ductal replication were increased synergistically in obese diabetic subjects. When surgical specimens of CP or nontumor tissue adjacent to PC were examined, even higher rates of the expression of replication markers were seen. These findings support the epidemiological studies that have identified CP, DM, and obesity as contributory to oncogenesis in the pancreas.

\section{Proposed mechanisms of diabetes-related pancreatic carcinogenesis}

Although epidemiological studies clearly indicate that DM is positively associated with an increased risk of PC, the molecular mechanism(s) of diabetes-related oncogenesis have not been fully elucidated. Insulin resistance and induced compensatory hyperinsulinemia are widely considered to be likely mechanisms to explain the association of DM and PC (Magruder et al. 2011, Li 2012). Several epidemiological studies have

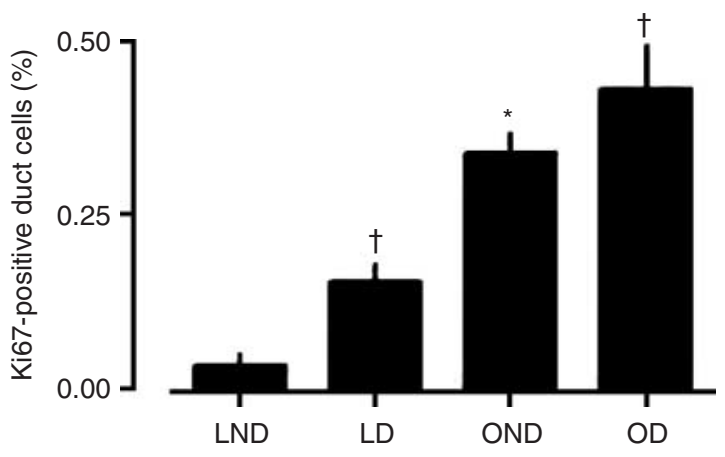

Figure 3 Number of cytokeratin-staining pancreatic ductal cells positive for Ki67, a marker of cellular replication, in autopsyharvested pancreata. LND, lean nondiabetic patients $(n=9)$; OND, obese nondiabetic patients $(n=11)$; LD, lean with type 2 diabetes $(n=12)$; OD, obese with type 2 diabetes $(n=13)$. Data are presented as mean \pm s.E.M. ${ }^{\star} P<0.0001$, LND vs OND. ${ }^{\dagger} P<0.001$, LD vs OD and LND vs LD. Reproduced, with permission, from Butler AE, Galasso R, Matveyenko A, Rizza RA, Dry S \& Butler PC 2010 Pancreatic duct replication is increased with obesity and type 2 diabetes in humans. Diabetologia 53 21-26. Copyright 2009 The Authors.

shown that insulin resistance status, characterized by hyperinsulinemia, is associated with an increased risk for a number of malignancies, including carcinomas of the breast, prostate, colon, and kidney. Hyperglycemia has also been shown to be a risk factor for PC. Batty et al. (2004) in England found evidence for a graded dose-response relationship between fasting glucose and the development of pancreatic or liver cancer resulting in mortality. Jee et al. (2005) similarly found a positive linear relationship between fasting glucose and the risk of developing PC across all categories of obesity in a cohort analysis of 1298385 Korean patients. In a study of 29133 Finnish smokers followed for over 10 years, Stolzenberg-Solomon et al. (2005) found that hyperglycemia, hyperinsulinemia, and insulin resistance were each associated with an increased risk of PC. The HR for PC for each entity did not increase significantly until more than 10 years of follow-up, suggesting that long-standing impairments were necessary for the development of PC.

Detailed reviews of these insulin-related mechanisms are provided by Pollak (2008) and Rozengurt et al. (2010). The insulin-like growth factor receptor 1(IGF1R), a tyrosine kinase receptor for IGF1 and 2, has been well documented in cell culture, animal studies, and humans to play a role in malignant transformation, progression, protection from apoptosis, and metastasis in a variety of malignancies. In addition, the hormone insulin and its tyrosine kinase receptor (insulin receptor (IR)) have been documented both in vitro and in vivo to play a key role in cancer biology (Frasca et al. 2008). Chronic hyperinsulinemia is a 
possible factor favoring cancer initiation and/or progression in diabetic patients due to the mitogenic effect of insulin. Insulin/IGF1 could activate the PI3K/ Akt/mammalian target of rapamycin (mTOR) signaling pathway by activation of IR substrates $1-4$, which contribute to the development of cancers including PC (Kornmann et al. 1998). Recent reports indicate that IR is overexpressed in several human malignancies and one of the two IR isoforms (IR-A) is especially overexpressed in pancreatic adenocarcinoma. The IRs expressed in malignant tissue also have the capacity to form a hybrid receptor with the IGF1R (Belfiore 2007). By binding to hybrid receptors, insulin may stimulate specific IGF1R signaling pathways, which mediate cell proliferation, inhibition of apoptosis, and growth (Fig. 4). Furthermore, Han et al. (2011) recently found that high glucose promotes PC cell proliferation via the induction of epithelial growth factor (EGF) expression and transactivation of the EGF receptor.

In addition to activation of receptors linked to proliferative and anti-apoptotic pathways, other possible mechanisms have also been suggested as important mediators of pancreatic carcinogenesis. The DM and obesity-related effects on PC development may be mediated by oxidative stress and induced inflammatory responses (Li 2012). Inflammatory responses to external stimuli can accelerate proliferative and repair processes, and obesity itself may activate inflammatory signaling pathways (Greer \& Whitcomb 2009, Gallagher \& LeRoith 2010). Proinflammatory cytokines released from adipose tissue, known as adipokines, can promote angiogenesis, tumor progression, and metastasis (van Kruijsdijk et al. 2009).

\section{Evidence for increased risk of PC with insulin, insulin secretagogues, and incretin-based treatment}

Although the mortality attributable to cancer in DM is overshadowed by that due to cardiovascular disease, emerging data from basic and epidemiological studies suggest that insulin therapy may confer an added risk for cancer, perhaps mediated by signaling through the IGF1R (Azar \& Lyons 2010). In 2000, Ding et al. (2000) found that physiological concentrations of insulin increased PC cell proliferation as well as glucose use by activating MAP kinase, PI3 kinase, and GLUT1 expression. In 2003, Bonelli et al. (2003) in Italy reported a case-control study in which the effect of

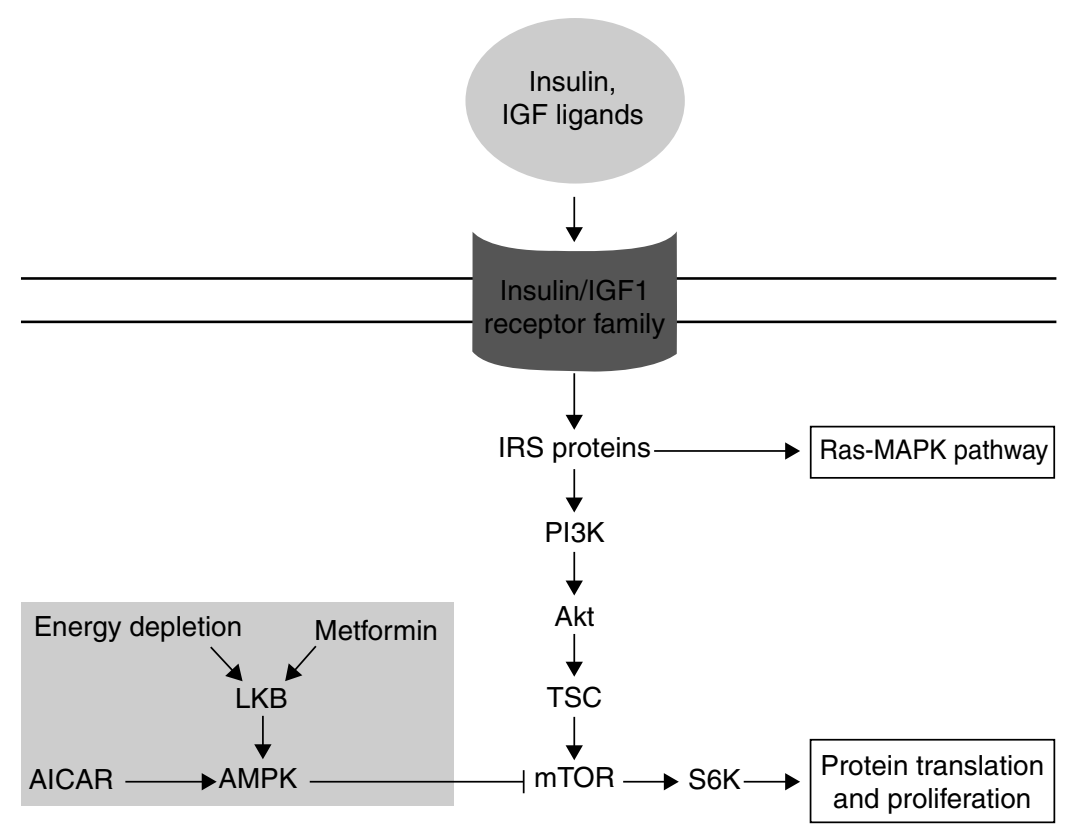

Figure 4 Insulin, insulin-like growth factor 1 (IGF1), and IGF2 mediation of translation and proliferation, and the effects of metformin on these pathways. Phosphorylation of insulin receptor substrate (IRS) proteins by insulin/IGF receptors activates phosphatidylinositol-3 kinase ( $\mathrm{PI} 3 \mathrm{~K})$ and the Ras-MAP-kinase signaling network. PI3K activates Akt that regulates protein synthesis and replication through the intermediate mammalian target of rapamycin (mTOR). Energy depletion or the drug metformin results in activation of AMP protein kinase (AMPK) through the intermediate liver kinase B1 (LKB). In the liver, AMPK activation results in diminished hepatic glucose production, which results in lower levels of circulating insulin. In the pancreas and elsewhere, AMPK inhibits mTOR signaling. Modified, with permission, from Magruder JT, Elahi D \& Andersen DK 2011 Diabetes and pancreatic cancer: chicken or egg? Pancreas 40 339-351. Copyright 2011 American Pancreatic Association and Japan Pancreas Society. 
type of treatment for DM on the subsequent development of PC was assessed. Two hundred and forty four patients with documented pancreatic carcinoma and 459 controls were assessed to determine whether insulin therapy or non-insulin therapy affected the subsequent rate of PC development. These investigators found that although DM was associated with a 2.86-fold increase in the risk for PC, the risk increased to 6.49 -fold for those treated with insulin, compared with 2.12-fold for those treated with oral hypoglycemic agents. Furthermore, although the duration of insulin treatment had no effect on the high-risk ratio (RR), longer duration of oral hypoglycemic therapy was associated with a lower RR for the development of PC. These findings were corroborated in 2006 by Bowker et al. (2006) who also found increased cancer-related mortality in T2DM patients treated with insulin or sulfonylureas. In the 2010 multinational case-control study by Maisonneuve et al. (2010), a history of DM conveyed an increased RR for PC overall (2.16), which was 6.68 for those whose history of DM started within 1 year of the diagnosis of cancer, falling to 1.28 for those whose diabetic history had existed for more than 10 years. In addition, the type of treatment for the DM was found to have a differential effect, with those who had been treated with insulin having an RR of 3.54, while those who had been treated only with oral agents having an RR of 1.78. These findings confirmed those of Bonelli et al. who similarly found a higher risk associated with insulin treatment than with non-insulin therapy. The higher risk seen with insulin treatment in the case-control studies of Maisonneuve et al. and Bonelli et al. may reflect a direct effect of insulin on tumor cell proliferation as insulin therapy would also be expected to produce periods of hyperinsulinemia. In addition, however, other factors may have contributed to the results, including length of treatment and the degree of hyperglycemia present, both of which would be expected to be greater in insulin-requiring patients. Carstensen et al. (2012) recently analyzed the effect of diabetes and diabetic therapy on cancer incidence in the Danish health system over a 27-year period and noted that the adverse effects of insulin treatment were quite modest. Therefore, caution has been advised in the acceptance of a cancer-promoting effect of insulin until further data are available (Gerstein 2010, Giovannucci et al. 2010, Hernandez-Diaz \& Adami 2010).

Insulin therapy has also been associated with a greater than expected incidence of breast cancer and other malignancies (Home \& Lagarenne 2009, Jonasson et al. 2009), however, and insulin secretagogues have similarly been implicated in an increased incidence of PC. Case-control studies indicate an increased risk of cancer overall in T2DM patients treated with sulfonylureas (Bowker et al. 2006, Monami et al. 2009), and studies of PC in particular indicate that sulfonylurea therapy confers an increased risk (Currie et al. 2009, Li et al. 2009).

Incretin-based therapies (glucagon-like peptide-1 (GLP1) analogues and inhibitors of didpeptidyl peptidase-IV, the enzyme that metabolizes GLP1) are the newest form of insulin secretagogue treatment of T2DM. No long-term epidemiological studies have yet been reported of their effect on the incidence of PC due to the relatively short period of clinical availability of these agents. However, laboratory studies suggest an adverse effect of these agents on the development of pre-neoplastic or malignant lesions of the pancreas, possibly related to the growth-promoting effects of GLP1 and its analog exendin-4. Matveyenko et al. (2009) described the effects of sitagliptin, a DDP-IV inhibitor, on pancreatic ductal cell proliferation and $\beta$-cell mass in the human islet amyloid polypeptide (HIP) transgenic model of T2DM in rats. Sitagliptin was seen to induce $\beta$-cell replication, $\beta$-cell apoptosis, pancreatic ductal metaplasia, and a fourfold increase in duct cell proliferation, all effects that were blocked by concurrent metformin administration (Fig. 5).

Gier et al. (2012) recently reported that the GLP1 analog exendin- 4 increased duct cell replication and increased the development of dysplastic pancreatic intraepithelial neoplasia (PanIN) lesions in a rat model in which activated Kras ${ }^{\text {G12D }}$ was induced. These investigators found that pancreatic duct glands (thought to be precursors of PanINs) in both rats and humans contain GLP1 receptors and are increased by treatment with exendin-4.

GLP1 and its analogs have been shown to increase expression of the transcription factor pancreaticduodenal homeobox-1 (PDX1; Perfetti et al. 2000, Stoffers et al. 2000). PDX1 is critical for normal pancreatic development and has been shown to be overexpressed in PC (Koizumi et al. 2003, Wang et al. 2005). Furthermore, PDX1 increases cell proliferation, invasion, and colony formation of transformed cell lines in vitro and stimulates $\mathrm{PC}$ formation in severe combined immunodeficiency (SCID) mice, thereby fulfilling criteria as an oncogene (Liu et al. 2011). The gene NR5A2 (also known as LRH1) has been identified as a PC susceptibility gene (Petersen et al. 2010) and is a target gene of PDX1 expression (Annicotte et al. 2003). PDX1-expressing endocrine cells can be transformed into a malignant, ductal cell phenotype after induction of pancreatitis by cerulein in mice (Gidekel Friedlander et al. 2009), which supports the epidemiological findings of a striking association of $\mathrm{CP}$ with the 
(a)
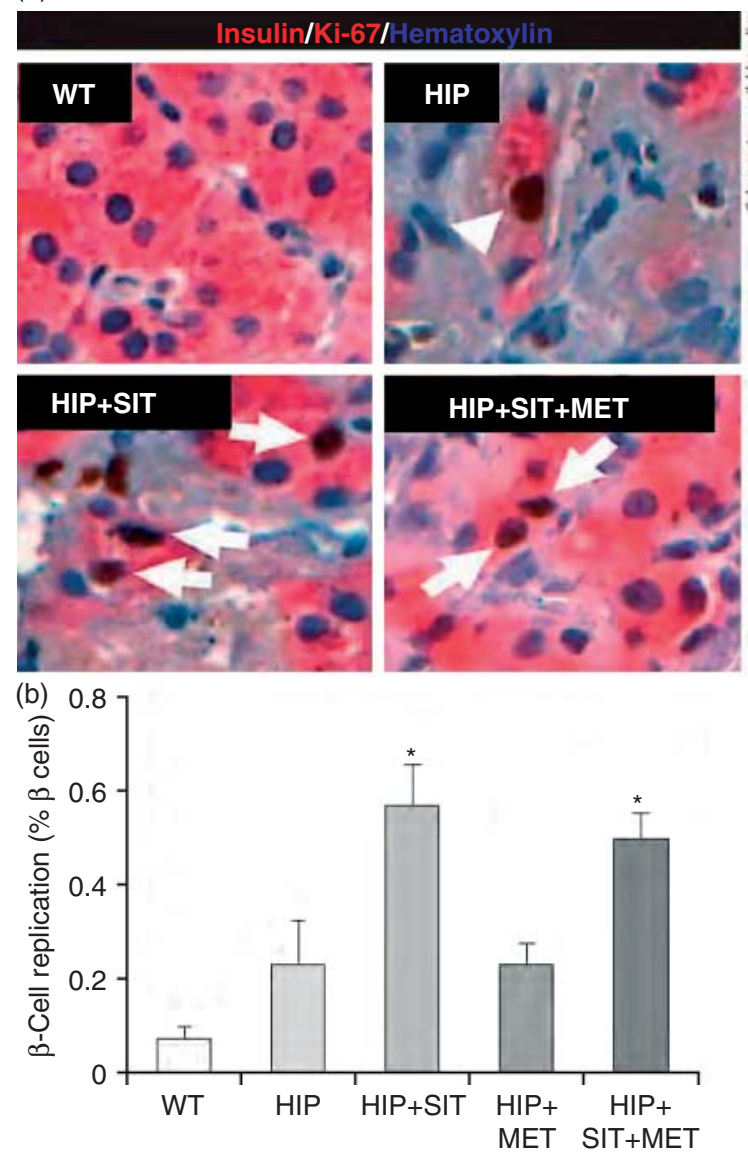

Figure 5 Effects of sitagliptin and metformin on $\beta$-cell replication. (Panel a) Example of islets stained for insulin (pink), the replication marker Ki67 (brown), and nuclear stain hematoxylin (blue) in wild-type (WT) and transgenic rats expressing human islet amyloid polypeptide (HIP), a model of type 2 diabetes, treated with sitagliptin $(200 \mathrm{mg} / \mathrm{kg}$ per day; HIP + SIT) or metformin $(200 \mathrm{mg} / \mathrm{kg}$ per day; HIP + MET), or both (HIP + $\mathrm{SIT}+\mathrm{MET}$ ) for 12 weeks. (Panel b) Frequency of $\beta$-cell replication in WT rats $(n=7)$, HIP rats $(n=8)$, HIP rats treated with SIT $(n=8)$, HIP rats treated with MET $(n=9)$, or HIP rats treated with both SIT and MET $(n=8)$. ${ }^{*} P<0.05$ vs WT, HIP, and HIP + MET groups. Arrows indicate Ki67-positive cells.

Reproduced, with permission, from Matveyenko AV, Dry S, Cox HI, Moshtaghian A, Gurlo T, Galasso R, Butler AE \& Butler PC 2009 Beneficial endocrine but adverse exocrine effects of sitagliptin in the human islet amyloid polypeptide transgenic rat model of type 2 diabetes: interactions with metformin. Diabetes 58 1604-1615. Copyright 2009, American Diabetes Association.

development of PC (Greer \& Whitcomb 2009). These findings suggest that Kras activation, either by genetic or nongenetic (inflammatory) events, may therefore activate neoplastic transformation within the pancreas to PDX1-expressing islet and/or ductal cells. Agents that increase PDX1 expression, such as GLP1 and its analogs, may therefore facilitate this process.

Most recently, Elashoff et al. (2011) examined the database of adverse outcomes reported to the US Food and Drug Administration and discovered that compared with other antidiabetic therapies, the use of sitagliptin or the GLP1 analog exenatide was associated with a two- to three-fold increase in the reporting incidence of PC. Although subject to multiple methodological limitations, these findings nevertheless raise concerns regarding an increased risk for pancreatitis and PC with GLP1-based therapy. Further epidemiological studies are clearly needed to define the possible hazards of incretin-based antidiabetic therapy, particularly in patients with T3cDM due to $\mathrm{CP}$ (Cui \& Andersen 2011).

\section{Evidence for decreased PC incidence in patients treated with metformin}

Although insulin and insulin secretagogue therapy is associated with an increased risk of PC, numerous clinical studies have demonstrated that the administration of metformin in DM patients exhibits a protective effect that is manifested by a decreasing incidence of different tumors and an improved prognosis of patients with cancer. Metformin has been widely used for the treatment of T2DM for almost 50 years, and its effectiveness has been attributed to enhanced sensitivity to insulin, rather than to an insulinotropic action. Its safety and efficacy are so well established that it is recommended as the first line of therapy for T2DM (Nathan et al. 2009). Evans et al. (2005) evaluated metformin use in diabetics who were admitted to hospital with a diagnosis of cancer between 1993 and 2001 in Tayside, Scotland, and compared this cohort with diabetic controls who were not admitted for cancer. They found that any exposure to metformin was associated with a significant reduction in cancer risk $(R R=0.77)$. The same group subsequently examined the database of all diabetic patients in the region and compared outcomes based on the national registry of cancer deaths (Libby et al. 2009). When the outcome of 4804 metformin users was compared with 4085 nonusers, a reduced risk (RR 0.63 ) for cancer mortality was found among diabetic patients treated with metformin, whereas a (nonsignificantly) increased risk of cancer mortality was seen among insulin and sulfonylurea users. Li et al. (2009) analyzed 978 patients with PC, including 259 diabetics, and 863 controls, including 109 diabetics, to assess the effects of diabetes treatment on the risk of PC. They found that whereas insulin treatment was associated with an increased risk (RR 2.78 for insulin users of more than 5 years), metformin therapy was associated with a $70 \%$ decreased risk (RR 0.30) for similar long-term users of the drug. The implications 
are further supported by a more recent cohort study from Taiwan in which metformin users were found to have a $85 \%$ decreased risk of pancreatic malignancy (HR 0.15, 95\% CI: 0.03-0.79; Lee et al. 2011b). Sadeghi et al. (2011) performed a retrospective cohort study of 302 patients to investigate the survival benefit of metformin in patients with DM and pancreatic malignancy. They report the median survival to be longer in metformin users when compared with nonusers: 16.6 vs 11.5 months $(P=0.0044)$. They also report a $33 \%$ decreased risk of death in patients who used metformin compared with those who did not. In addition to studies of its anticancer effects in PC, metformin has also been shown to have anticancer effectiveness in diabetic breast cancer patients (Jiralerspong et al. 2009, Chlebowski et al. 2012) and in colon cancer patients (Zhang et al. 2011).

These clinical studies corroborated the initial findings of Schneider et al. (2001) who found a therapeutic effect of metformin in a hamster model of carcinogen-induced PC. In these animals, metformin treatment significantly decreased islet cell hyperplasia and pancreatic ductal proliferation and completely prevented the development of pancreatic adenocarcinoma. Additional evidence showed that metformin can inhibit PC cell growth and proliferation by disrupting the cross talk between insulin/IGF1Rs and G-proteincoupled receptors through the activation of the liver kinase B1-AMP (LKB1-AMP) AMPK pathway, which serves not only to suppress hepatic glucose production and reduce the need for insulin but also inhibits the signaling mechanisms that regulate cellular proliferation (Rozengurt et al. 2010). LKB1 is a known tumor suppressor that activates AMPK, a potent inhibitor of mTOR complex 1 , which serves as a regulator of protein synthesis and replication (see Fig. 4). Bao et al. (2012) found that metformin significantly decreased cell survival, clonogenicity, wound healing capacity, sphere-forming capacity (pancreatospheres), and increased disintegration of pancreatospheres in both gemcitabine-sensitive and gemcitabine-resistant PC cells. Metformin also decreased the expression of cancer stem cell (CSC) markers, CD44, EpCAM, EZH2, Notch1, Nanog, and Oct 4 and caused re-expression of miRNAs (let-7a, b, miR-26a, miR-101, and miR-200b,c) that are typically lost in PC. These results suggest that the biological effects of metformin as an antineoplastic agent are mediated through re-expression of miRNAs and decreased expression of CSC-specific genes that are affected by carcinogenesis, and numerous laboratory and clinical studies are now underway to examine the antitumor applications of metformin.

\section{Diabetes as a consequence (and harbinger) of PC The prevalence of diabetes is increased in PC patients}

Many cohort and case-control studies indicate that $25-50 \%$ of patients with a diagnosis of PC will have developed DM within 1-3 years before their diagnosis of malignancy (Huxley et al. 2005, Chari et al. 2008). This implies that recent-onset DM associated with $\mathrm{PC}$ is caused by pancreatic malignancy and suggests that $\mathrm{DM}$ is a biomarker of early-stage PC. The problem is that newonset DM, per se, is not a powerful-enough predictor of PC to stand alone as an indication for radiological or endoscopic screening, as $98 \%$ of patients with adult-onset DM will never develop PC (Chari et al. 2005a). Imaging protocols applied to patients with new-onset DM older than the age of 50 have not been shown to be either practical or reliable as an early detection method based on the studies in Japan (Ogawa et al. 2002), France (Damiano et al. 2004), and the USA (Chari et al. 2005a,b).

In addition to the frequent development of DM just proximate to the diagnosis of $\mathrm{PC}$, the concept that $\mathrm{PC}$ is a cause of new-onset DM is supported by several observations. Patients with premalignant pancreatic lesions from kindreds in which PC is highly prevalent typically have concurrent DM (Brentnall et al. 1999). Furthermore, new-onset DM associated with PC has been seen to resolve after the successful resection of the tumor (Permert et al. 1993, Fogar et al. 1994, Pannala et al. 2008; Fig. 6). In laboratory studies, PC-derived cell lines induce hyperglycemia in SCID mice (Basso et al. 1995), and a PC-derived S-100A8 N-terminal peptide has been identified as a diabetogenic agent (Basso et al. 2006).

Despite vigorous clinical investigation, no biomarker specific for PC-associated DM has been validated, and tumor markers such as carcinoembryonic antigen and carbohydrate antigen 19-9 are insufficiently sensitive to detect early-stage disease. Permert et al. (1994) identified elevated levels of islet amyloid polypeptide (IAPP), a $\beta$-cell peptide co-secreted with insulin, as a possible biomarker of PC and demonstrated that PC cells are capable of inducing IAPP release from $\beta$-cells (Ding et al. 1998), but Chari et al. (2001) subsequently showed that IAPP was not sufficiently sensitive to serve as a biomarker of PC. Using microarray analysis, Pfeffer et al. (2004) identified connexin 26, a gap junction protein, as being highly overexpressed in PC patients with DM. Using similar methods, Huang et al. (2010) identified two upregulated genes in 27 patients with PC-associated DM, vanin-1 and matrix metalloproteinase 9, that 


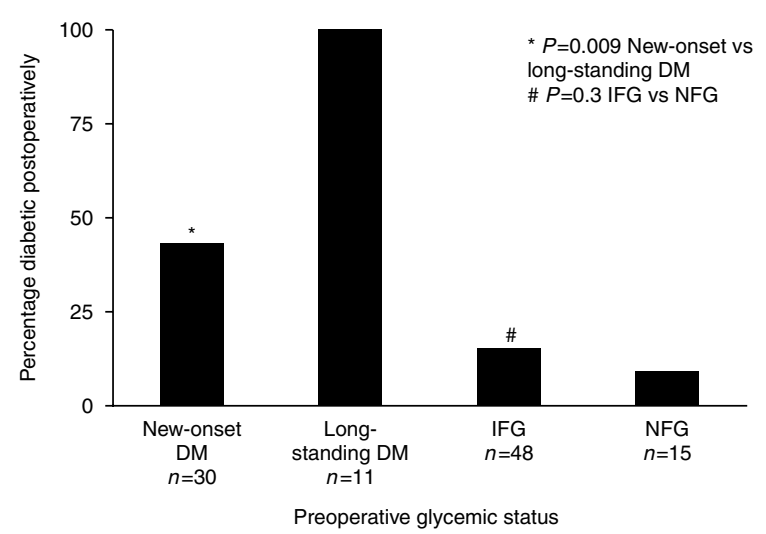

Figure 6 Prevalence of postoperative diabetes after pancreaticoduodenectomy for pancreatic cancer. Data for patients with new-onset diabetes (2-year duration), impaired fasting glucose (IFG), and normal fasting glucose (NFG) are shown: NFG, $126 \mathrm{mg} / \mathrm{dl}(7 \mathrm{mmol} / \mathrm{l})$. Whereas postoperative diabetes was seen in all long-standing diabetic patients, and in some patients with IFG and NFG, diabetes resolved in more than $50 \%$ of patients with new-onset diabetes despite removal of half of the $(\beta)$-cell mass. Reproduced, with permission, from Pannala R, Leirness JB, Bamlet WR, Basu A, Petersen GM \& Chari ST 2008 Prevalence and clinical profile of pancreatic cancerassociated diabetes mellitus. Gastroenterology 134 981-987. Copyright 2008 AGA Institute.

together showed the best correlation with the diagnosis. No large-scale studies have been reported yet regarding the sensitivity and specificity of these possible biomarkers.

\section{Pathogenesis of pancreatic carcinoma- associated diabetes}

The mechanism(s) responsible for the DM caused by PC are incompletely understood. Defects in insulin sensitivity and insulin secretory capacity have been identified in patients with PC-associated DM, and abnormalities in glucose metabolism in skeletal muscle and liver have been observed in vitro as well. These multiple abnormalities suggest that one or more humoral factors are likely involved in PC-associated DM, as reviewed by Pannala et al. (2009).

Animal models of carcinogen-induced PC exhibit both hyperinsulinemia (Liu et al. 2000) and insulin secretory impairments (Ahren \& Andren-Sandberg 1993, Permert et al. 2001), which implies that insulin resistance is an early event in PC-associated DM. Impaired sensitivity to insulin has been demonstrated in euglycemic glucose clamp studies and by means of the homeostasis model assessment method in patients with PC-associated DM (Cersosimo et al. 1991, Chari et al. 2005a), which improves after removal of the tumor despite reduced insulin secretory capacity after surgical resection (Permert et al. 1993, Pannala et al.
2008). Clinical studies on the pathophysiology of PC-associated DM have been confounded, however, by the inability of investigators to document whether the DM exhibited by each PC patient is preexisting T2DM or pancreatogenic (type 3c) DM caused by the tumor.

\section{Distinguishing T3CDM from T2DM}

Recalling that $\mathrm{T} 3 \mathrm{cDM}$ is the form of DM that is a consequence of pancreatic exocrine pathology and that $\mathrm{T} 3 \mathrm{cDM}$ is in many ways distinct from T2DM (see Table 1), the issue therefore becomes how to feasibly distinguish individuals with T3cDM from the vastly more prevalent T2DM, so as to identify the subset of high-risk patients in whom high-resolution imaging tests might feasibly identify suspicious areas within the pancreatic parenchyma.

A retrospective cohort study of 2122 diabetic patients suggested that PC developed within 3 years after the diagnosis of DM in $1 \%$ of the patients who were at least 50-year old (Chari et al. 2005a). Johnson et al. (2011) found that the diagnosis of PC was highest within 3 months following the onset of DM, and Aggarwal et al. (2012) showed that the duration of DM before the diagnosis of PC by primary care providers averaged 6.5 months. A study by Lee et al. (2011a) reported that compared with the control group, PC patients were, on average, older, had more weight loss, lower usual BMI, a greater family history of PC (3.3 vs $0.7 \% ; P=0.044)$, and had a lower family history of DM (13.9 vs $37.4 \% ; P<0.001)$. These authors concluded that PC-associated DM (T3cDM) could be discriminated from new-onset T2DM based on clinical features, such as the lack of a family history of DM, age 65 years or older, recent weight loss of $>2 \mathrm{~kg}$, or a premorbid or usual BMI $<25 \mathrm{~kg} / \mathrm{m}^{2}$. A definitive diagnosis of T3cDM, however, requires further testing for confirmation in patients who lack a history of pancreatic disease or a family history of PC. Fecal elastase-1 levels $<100 \mu \mathrm{g} / \mathrm{g}$ strongly suggest pancreatic exocrine impairments (Loser et al. 1996), but the most consistent laboratory finding in $\mathrm{T} 3 \mathrm{cDM}$ due to any cause is a deficiency of the pancreatic polypeptide (PP) response to ingested nutrients (Cui \& Andersen 2011, Magruder et al. 2011).

\section{PP deficiency: a marker of T3cDM}

PP is localized predominantly to islets in the ventral portion (head) of the pancreas and is promptly secreted in response to ingested nutrients. PP regulates the expression and availability of hepatic IRs, and hepatic insulin resistance due to PP deficiency is reversed by PP administration in animals and man (Andersen 2007). 
T3cDM secondary to cystic fibrosis, $\mathrm{CP}$, pancreatic malignancy, or pancreatic resection is uniformly characterized by a deficiency in the nutrient-stimulated release of PP (Fig. 7) and a defect in hepatic insulin sensitivity (Slezak \& Andersen 2001, Cui \& Andersen 2011). T2DM, on the other hand, is typically associated with an increase in basal and nutrient-stimulated levels of PP (Glaser et al. 1988). Furthermore, healthy elderly subjects with normal glucose tolerance also demonstrate elevations in basal and nutrient-stimulated levels of PP compared with younger subjects (Magruder et al. 2011; Fig. 8). Therefore, the discrimination of T3cDM from T2DM is based on the failure of plasma PP levels to increase after nutrient ingestion. Basal levels of PP in PP-deficient subjects are similar to basal levels in normal subjects, so a nutrient stimulus is required to confirm PP deficiency. Glucose ingestion is a relatively weak stimulus for PP release, whereas a mixed nutrient meal is a strong inducer of PP release. A standardized mixed-nutrient stimulus is 8 ounces of a liquid dietary supplement such as Ensure-Plus; peak levels of PP are seen within 30-60 min after ingestion. Studies are currently in progress to establish the prevalence of PP deficiency in PC patients with and without DM, but a diagnosis of new-onset T3cDM based on PP deficiency is a strong indicator that the patient is in a high-risk category for PC and warrants further investigation to identify a pancreatic parenchymal abnormality.

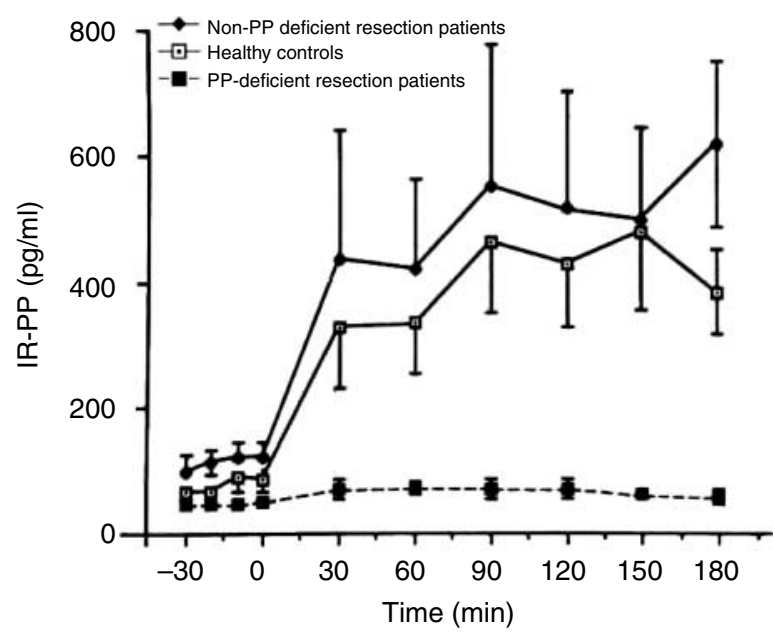

Figure 7 Serum PP responses to a test meal in eight normal control subjects (open boxes), four non-PP-deficient patients who had recovered from distal pancreatic resection performed for trauma (closed diamonds), and six PP-deficient patients who had recovered from proximal pancreatic resection performed for trauma (closed boxes, broken line). Means \pm s.E.M. are shown. Reproduced, with permission, from Magruder JT, Elahi D \& Andersen DK 2011 Diabetes and pancreatic cancer: chicken or egg? Pancreas 40 339-351. Copyright 2011 Lippincott Williams \& Wilkins, Inc.

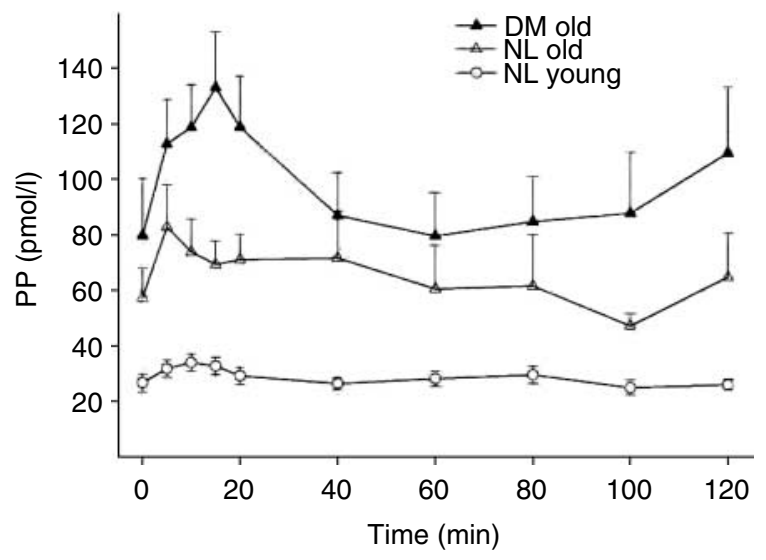

Figure 8 Serum PP responses to $75 \mathrm{~g}$ glucose ingested at time $=0$ in ten healthy young (age younger than 40 years; NL young), 19 healthy elderly (age older than 65 years) with normal glucose tolerance (NL old), and 21 elderly subjects with T2DM (DM old). Data are shown as mean \pm s.E.M. Reproduced, with permission, from Magruder JT, Elahi D \& Andersen DK 2011 Diabetes and pancreatic cancer: chicken or egg? Pancreas 40 339-351. Copyright 2011 Lippincott Williams \& Wilkins, Inc.

\section{Prevalence of T3cDM}

Patients who have a known history of pancreatic disease and who are also diabetic require special surveillance for PC. The most common cause of $\mathrm{T} 3 \mathrm{cDM}$ is $\mathrm{CP}$, which harbors a 10 - to 20 -fold increased risk of PC; the combination of $\mathrm{CP}$ and $\mathrm{DM}$ increases this risk 33-fold. Unless drug side effects (principally gastrointestinal sensitivity) or a contraindication (such as renal insufficiency) is present, metformin should be prescribed to all $\mathrm{T} 3 \mathrm{cDM}$ patients, even if other antidiabetic drugs such as insulin have to be added for adequate glycemic control (Cui \& Andersen 2011).

T3cDM had been estimated to account for only 1-2\% of all diabetic patients in North America (Ganda 2005) but is known to affect as many as $15-20 \%$ of diabetic patients in the Indian and Southeast Asian continents, where tropical or fibrocalcific pancreatitis is endemic (Abu-Bakare et al. 1986). In a careful evaluation of almost 2000 diabetic patients referred to an academic medical center in Germany, Hardt et al. (2008) discovered that $8 \%$ of all diabetic patients harbored T3cDM (Fig. 9). Furthermore, Ewald et al. (2011) subsequently showed that nearly half of the T3cDM patients had been previously misdiagnosed as either T1DM $(6 \%)$ or T2DM (40\%). With the advent of improved imaging methods to detect pancreatic pathology, and the availability of a practical screening method to quantify exocrine pancreatic function, previous estimates of the prevalence of T3cDM are now understood to have been spuriously low (Ewald et al. 2009). 
(a)

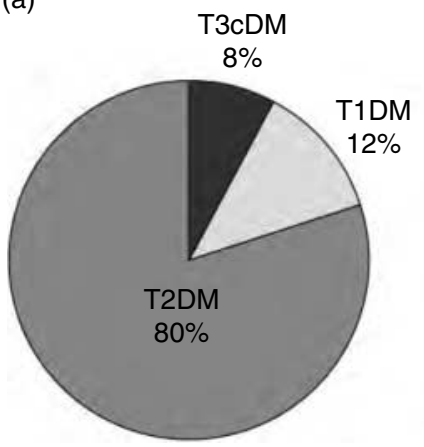

Distribution of T1DM, T2DM and T3cDM (b)

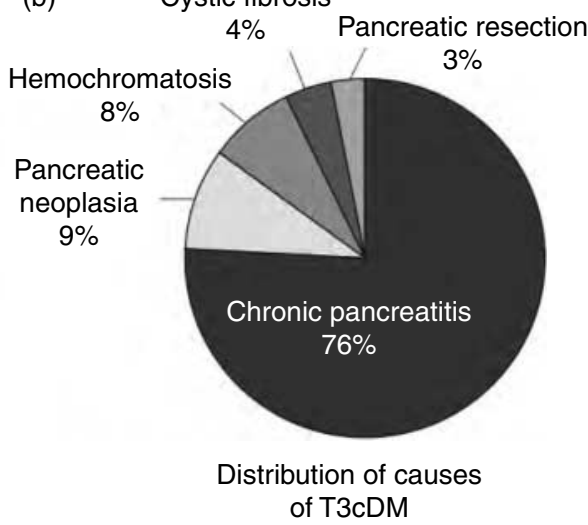

Figure 9 Distribution of types of diabetes (a) and causes of type 3c (pancreatogenic) diabetes (b) based on the studies of 1922 diabetic patients referred to an academic medical center in Germany. Reproduced, with permission, from Cui Y \& Andersen DK 2011 Pancreatogenic diabetes: special considerations for management. Pancreatology 11 279-294. Copyright 2011 S Karger AG. Data from Hardt et al. (2008).

In the German cohort study, $78.5 \%$ of T3cDM patients had $\mathrm{CP}$ as the underlying etiology of their T3cDM. In an older study of 500 patients with CP due to alcoholism, DM developed in $83 \%$ within 25 years of the clinical onset of $\mathrm{CP}$, and more than half of the diabetic patients ultimately required insulin therapy (Malka et al. 2000). With the increasing prevalence of CP worldwide (Rothenbacher et al. 2005), the population of patients at greatest risk for the development of PC is clearly expanding. Therefore, an aggressive approach to the identification, surveillance, and management of patients at high-risk for PC is an important strategy in order to reduce the mortality rate of $\mathrm{PC}$.

\section{Drugs used to treat PC may cause diabetes}

A recently emerging issue is the possible adverse effect on glucose metabolism of anticancer therapies. Cancer patients commonly exhibit hyperglycemic states or DM following glucocorticoid administration (Saylor \& Smith 2009). The increasing use of targeted chemotherapy directed against components of the IGF1 pathway may amplify the frequency of anticancer drug-related diabetes. IGF1 and insulin, their receptors, and their intracellular signaling pathways share multiple similarities. Likewise, the biological (metabolic and mitogenic) effects of insulin and IGFs overlap. Hyperglycemia was observed in some patients enrolled in studies with an anti-IGF1R antibody (Haluska et al. 2006, Lacy et al. 2008). This is likely to be a consequence of a compensatory increase in the circulating concentration of GH after IGF1 blockade, with the consequent increase in $\mathrm{GH}$-induced insulin resistance (del Rincon et al. 2007). Hyperglycemia, hypertriglyceridemia, and hypercholesterolemia were also observed in about $20 \%$ of patients treated with the mTOR inhibitors (Bellmunt et al. 2008). Recent reports also documented increased blood glucose levels in $26 \%$ of temsirolimus-treated patients (Bellmunt et al. 2008, Malizzia \& Hsu 2008). However, tyrosine kinase inhibitor therapy directed at IGF1Rs was associated with less hyperglycemia than IGF1R-blocking antibodies (Pollak 2008). At present, insufficient data are available to assess the possible diabetogenic effects of phosphoinositol-3-kinase and AKT inhibitor therapy.

\section{Conclusions and clinical recommendations}

Epidemiological data clearly demonstrate an etiological link between long-standing T2DM, and probably T1DM, and PC. Successful treatment of T2DM and obesity has been shown to reduce the risk of PC, but treatment with insulin, insulin analogs, and insulin secretagogues increases or maintains the risk. Metformin has been shown to reduce the risk of PC owing to its antidiabetic and antineoplastic actions and should be considered as first-line therapy in all new-onset DM patients over the age of 50. In addition, metformin, as well as lifestyle alterations, have been shown to reduce the incidence of T2DM when administered to obese individuals with impaired glucose tolerance (Knowler et al. 2002, Cefalu 2012). Such successful prevention strategies need to be more fully used in order to reverse the increasing incidence of PC.

New-onset DM can be a consequence, and therefore a harbinger, of PC. DM caused by PC is classified as 
T3cDM, which occurs in up to $30 \%$ of patients with PC. If a new-onset DM patient does not have family history of DM, is aged 65 years or older, or has had a stable BMI $<25 \mathrm{~kg} / \mathrm{m}^{2}$, PC-associated DM (T3cDM) should be considered, especially within 3 months following onset of DM. If the patient has a family history of two or more relatives with PC, highresolution imaging (preferably computer tomographic scanning followed by endoscopic ultrasound) of the pancreas should be considered to identify suspicious areas within the parenchyma (Brentnall et al. 1999).

If no family history of $\mathrm{PC}$ is present, $\mathrm{T} 3 \mathrm{cDM}$ can be confirmed by documenting the absence of a rise in PP levels after a test meal or liquid mixed-nutrient challenge. Patients with confirmed T3cDM, with or without a history of pancreatic disease, are candidates for periodic high-resolution pancreatic imaging to detect early pathological changes within the pancreas. With an aggressive approach to distinguishing T3cDM from T2DM, many cases of early PC may be able to be identified when curative removal of the tumor is still possible.

\section{Declaration of interest}

The authors declare that there is no conflict of interest that could be perceived as prejudicing the impartiality of the review reported.

\section{Funding}

This review did not receive any specific grant from any funding agency in the public, commercial or not-for-profit sector.

\section{References}

Abu-Bakare A, Taylor R, Gill GV \& Alberti KG 1986 Tropical or malnutrition-related diabetes: a real syndrome? Lancet 1 1135-1138. (doi:10.1016/S01406736(86)91846-5)

Adams TD, Stroup AM, Gress RE, Adams KF, Calle EE, Smith SC, Halverson RC, Simper SC, Hopkins PN \& Hunt SC 2009 Cancer incidence and mortality after gastric bypass surgery. Obesity 17 796-802. (doi:10.1038/ oby.2008.610)

Aggarwal G, Rabe KG, Pedersen GM \& Chari ST 2012 New-onset diabetes in pancreatic cancer: a study in the primary care setting. Pancreatology 12 156-161. (doi:10.1016/j.pan.2012.02.003)

Ahren B \& Andren-Sandberg A 1993 Glucose tolerance and insulin secretion in experimental pancreatic cancer in the Syrian hamster. Research in Experimental Medicine 193 21-26. (doi:10.1007/BF02576207)
American Diabetes Association 2011 Diagnosis and classification of diabetes. Diabetes Care 34 (suppl 1) S62-S69. (doi:10.2337/dc11-S062)

Andersen DK 2007 Mechanisms and emerging treatments of the metabolic complications of chronic pancreatitis. Pancreas 35 1-15. (doi:10.1097/mpa.0b013e31805 d01b0)

Annicotte JS, Fayard E, Swift GH, Selander L, Edlund H, Tanaka T, Kodama T, Schoonjans K \& Auwerx J 2003 Pancreatic-duodenal homeobox-1 regulates expression of liver homolog 1 during pancreatic development. Molecular and Cellular Biology 23 6713-6724. (doi:10.1128/MCB.23.19.6713-6724.2003)

Arslan AA, Helzlsouer KJ, Kooperberg C, Shu XO, Steplowski E, Bueno-de-Mesquita HB, Fuchs CS, Gross MD, Jacobs EJ, Lacroix AZ et al. 2010 Anthropometric measures, body mass index, and pancreatic cancer: a pooled analysis from the Pancreatic Cancer Cohort Consortium (PanScan). Archives of Internal Medicine 170 791-802. (doi:10.1001/archinternmed.2010.63)

Azar M \& Lyons TJ 2010 Diabetes, insulin treatment, and cancer risk: what is the evidence? F1000 Medicine Reports 2 4. (doi:10.3410/M2-4)

Bao B, Wang Z, Ali S, Ahmad A, Azmi AS, Sarkar SH, Banerjee S, Kong D, Li Y, Thakur S et al. 2012 Metformin inhibits cell proliferation, migration and invasion by attenuating CSC function mediated by deregulating miRNAs in pancreatic cancer cells. Cancer Prevention Research 5 355-364. (doi:10.1158/19406207.CAPR-11-0299)

Basso D, Brigato L, Veronesi A, Panozzo MP, Amadori A \& Plebani M 1995 The pancreatic cancer cell line MIA $\mathrm{PaCa} 2$ produces one or more factors able to induce hyperglycemia in SCID mice. Anticancer Research 15 2585-2588.

Basso D, Greco E, Fogar P, Pucci P, Flagiello A, Baldo G, Giunco S, Valerio A, Navaglia F, Zambon CF et al. 2006 Pancreatic cancer-derived S-100A8 N-terminal peptide: a diabetes cause? Clinica Chimica Acta 372 120-128. (doi:10.1016/j.cca.2006.03.027)

Batty GD, Shipley MJ, Marmot M \& Smith GD 2004 Diabetes status and post-load plasma glucose concentration in relation to site-specific cancer mortality: findings from the original Whitehall study. Cancer Causes \& Control 15 873-881. (doi:10.1007/s10552-0041050-z)

Belfiore A 2007 The role of insulin receptor isoforms and hybrid insulin/IGF-I receptors in human cancer. Current Pharmaceutical Design 13 671-686. (doi:10.2174/ 138161207780249173)

Bellmunt J, Szczylik C, Feingold J, Strahs A \& Berkenblit A 2008 Temsirolimus safety profile and management of toxic effects in patients with advanced renal cell carcinoma and poor prognostic features. Annals of Oncology 19 1387-1392. (doi:10.1093/annonc/ mdn066) 
Ben Q, Xu M, Ning X, Liu J, Hong S, Huang W, Zhang H \& Li Z 2011 Diabetes mellitus and risk of pancreatic cancer: a meta-analysis of cohort studies. European Journal of Cancer 47 1928-1937. (doi:10.1016/j.ejca.2011.03.003)

Bonelli L, Aste H, Bovo P, Cavallini G, Felder M, Gusmaroli R, Morandini E, Ravelli P, Briglia R, Lombardo L et al. 2003 Exocrine pancreatic cancer, cigarette smoking, and diabetes mellitus: a case-control study in northern Italy. Pancreas 27 143-149. (doi:10.1097/00006676-200308000-00007)

Bowker SL, Majumdar SR, Veugelers P \& Johnson JA 2006 Increased cancer-related mortality for patients with type 2 diabetes who use sulfonylureas or insulin. Diabetes Care 29 254-258. (doi:10.2337/diacare.29.02.06.dc05-1558)

Brentnall TA, Bronner MP, Byrd DR, Haggitt RC \& Kimmey MB 1999 Early diagnosis and treatment of pancreatic dysplasia in patients with a family history of pancreatic cancer. Annals of Internal Medicine 131 247-255.

Butler AE, Galasso R, Matveyenko A, Rizza RA, Dry S \& Butler PC 2010 Pancreatic duct replication is increased with obesity and type 2 diabetes in humans. Diabetologia 53 21-26. (doi:10.1007/s00125-009-1556-8)

Calle EE, Rodriguez C, Walker-Thurmond K \& Thun MJ 2003 Overweight, obesity, and mortality from cancer in a prospectively studied cohort of U.S. adults. New England Journal of Medicine 348 1625-1638. (doi:10.1056/ NEJMoa021423)

Carstensen B, Witte DR \& Friis S 2012 Cancer occurrence in Danish diabetic patients: duration and insulin effects. Diabetologia 55 948-958. (doi:10.1007/s00125-011-2381-4)

Cefalu WT 2012 Steps toward the meaningful translation of prevention strategies for Type 2 diabetes. Diabetes Care 35 663-665. (doi:10.2337/dc12-0119)

Cersosimo E, Pisters PWT, Pesola G, McDermott K, Bajorunas D \& Brennan MF 1991 Insulin secretion and action in patients with pancreatic cancer. Cancer 67 486-493. (doi:10.1002/1097-0142(19910115)67:2< 486::AID-CNCR2820670228>3.0.CO;2-1)

Chari ST, Klee GG, Miller LJ, Raimondo M \& DiMagno EP 2001 Islet amyloid polypeptide is not a satisfactory marker for detecting pancreatic cancer. Gastroenterology 121 640-645. (doi:10.1053/gast.2001.27210)

Chari ST, Leibson CL, Rabe KG, Ransom J, de Andrade M \& Petersen GM 2005a Probability of pancreatic cancer following diabetes: a population-based study. Gastroenterology 129 504-511.

Chari ST, Zapiach M, Yadav D \& Rizza RA 2005b Beta-cell function and insulin resistance evaluated by HOMA in pancreatic cancer subjects with varying degrees of glucose intolerance. Pancreatology 5 229-233. (doi:10.1159/000085276)

Chari ST, Leibson CL, Rabe KG, Timmons LJ, Ransom J, de Andrade M \& Petersen GM 2008 Pancreatic cancer associated diabetes mellitus: prevalence and temporal association with diagnosis of cancer. Gastroenterology 134 95-101. (doi:10.1053/j.gastro.2007.10.040)
Chlebowski RT, McTiernan A, Wactawski-Wende J, Manson JE, Rohan AKT, Ipp E, Kaklamani VJ, Vitolins M, Wallace R, Gunter M et al. 2012 Diabetes, metformin, and breast cancer in post-menopausal women. Journal of Clinical Oncology 30 2844-2852. (doi:10.1200/JCO.2012.42.3319)

Christou NV, Lieberman M, Sampalis F \& Sampalis JS 2008 Bariatric surgery reduces cancer risk in morbidly obese patients. Surgery for Obesity and Related Diseases 4 691-695. (doi:10.1016/j.soard.2008.08.025)

Cui Y \& Andersen DK 2011 Pancreatogenic diabetes: special considerations for management. Pancreatology 11 279-294. (doi:10.1159/000329188)

Currie CJ, Poole CD \& Gale EA 2009 The influence of glucose-lowering therapies on cancer risk in type 2 diabetes. Diabetologia 52 1766-1777. (doi:10.1007/ s00125-009-1440-6)

Damiano J, Bordier L, Le Berre JP, Margery J, Dupuy O, Mayaudon H \& Bauduceau B 2004 Should pancreas imaging be recommended in patients over 50 years old when diabetes is discovered because of acute symptoms? Diabetes \& Metabolism 30 203-207. (doi:10.1016/ S1262-3636(07)70111-8)

Ding X, Flatt PR, Permert J \& Adrian TE 1998 Pancreatic cancer cells selectively stimulate islet beta cells to secrete amylin. Gastroenterology 114 130-138. (doi:10.1016/ S0016-5085(98)70641-9)

Ding XZ, Fehsenfeld DM, Murphy LO, Permert J \& Adrian TE 2000 Physiological concentrations of insulin augment pancreatic cancer cell proliferation and glucose utilization by activating MAP kinase, PI3 kinase and enhancing GLUT-1 expression. Pancreas 21 310-320. (doi:10.1097/00006676-200010000-00014)

Edwards BK, Brown ML, Wingo PA, Howe HL, Ward E, Ries LA, Schrag D, Jamison PM, Jemal A, Wu XC et al. 2005 Annual report to the nation on the status of cancer, 1975-2002, featuring population-based trends in cancer treatment. Journal of the National Cancer Institute 97 1407-1427. (doi:10.1093/jnci/dji289)

Elashoff M, Matveyenko AV, Gier B, Elashoff R \& Butler PC 2011 Pancreatitis, pancreatic, and thyroid cancer with glucagon-like peptide-1-based therapies. Gastroenterology 141 150-156. (doi:10.1053/j.gastro.2011.02.018)

Evans JM, Donnelly LA, Emslie-Smith AM, Alessi DR \& Morris AD 2005 Metformin and reduced risk of cancer in diabetic patients. BMJ 330 1304-1305. (doi:10.1136/bmj. 38415.708634.F7)

Ewald N, Raspe A, Kaufmann C, Bretzel RG, Kloer HU \& Hardt PD 2009 Determinants of exocrine pancreatic function as measured by fecal elastase 1 concentrations (FEC) in patients with diabetes mellitus. European Journal of Medical Research 14 118-122.

Ewald N, Kaufmann C, Raspe A, Kloer HU, Bretzel RG \& Hardt PD 2011 Prevalence of diabetes mellitus secondary to pancreatic diseases (type 3c). Diabetes/Metabolism Research and Reviews 28 338-342. (doi:10.1002/ dmrr.2260) 
Fogar P, Pasquali C, Basso D, Sperti C, Panozzo MP, Tessari G, D’Angeli F, Del Favero G \& Plebani M 1994 Diabetes mellitus in pancreatic cancer follow-up. Anticancer Research 14 2827-2830.

Frasca F, Pandini G, Sciacca L, Pezzino V, Squatrito S, Belfiore A \& Vigneri R 2008 The role of insulin receptors and IGF-I receptors in cancer and other diseases. Archives of Physiology and Biochemistry 114 23-37. (doi:10.1080/ 13813450801969715)

Gallagher EJ \& LeRoith D 2010 Insulin, insulin resistance, obesity, and cancer. Current Diabetes Reports 10 93-100. (doi:10.1007/s11892-010-0101-y)

Ganda OP 2005 Secondary forms of diabetes. In Joslin's Diabetes Mellitus, 14th edn, pp 477-492. Eds CR Kahn, GC Weir, GL King, AM Jacobson, AC Moses \& RJ Smith. Philadelphia, PA, USA: Lippincott, Williams and Wilkins.

Gerstein HC 2010 Does insulin therapy promote, reduce, or have a neutral effect on cancers? Journal of the American Medical Association 303 446-447. (doi:10.1001/jama. 2010.60)

Gidekel Friedlander SY, Chu GC, Snyder EL, Gimius N, Dibelius G, Crowley D, Vasile E, DePinho RA \& Jacks T 2009 Context-dependent transformation of adult pancreatic cells by oncogenic K-Ras. Cancer Cell 16 379-389. (doi:10.1016/j.ccr.2009.09.027)

Gier B, Matveyenko AV, Kirakossian D, Dawson D, Dry SM \& Butler PC 2012 Chronic GLP-1 receptor activation by exendin-4 induces expansion of pancreatic duct glands in rats and accelerates formation of dysplastic lesions and chronic pancreatitis in the Kras ${ }^{\text {G12D }}$ mouse model. Diabetes 61 1250-1262. (doi:10.2337/db11-1109)

Giovannucci E, Harlan DM \& Archer MC 2010 Diabetes and cancer: a consensus report. CA: A Cancer Journal for Clinicians 60 207-221. (doi:10.3322/caac.20078)

Glaser B, Zoghlin G, Pienta K \& Vinik AI 1988 PP response to secretin in obesity: effects of glucose intolerance. Hormone and Metabolic Research 20 288-292. (doi:10.1055/s-2007-1010817)

Greer JB \& Whitcomb DC 2009 Inflammation and pancreatic cancer: an evidence-based review. Current Opinion in Pharmacology 9 411-418. (doi:10.1016/j.coph.2009.06.011)

Gumbs AA 2008 Obesity, pancreatitis, and pancreatic cancer. Obesity Surgery 18 1183-1187. (doi:10.1007/s11695008-9599-3)

Haluska P, Carboni JM, Loegering DA, Lee FY, Wittman M, Saulnier MG, Frennesson DB, Kalli KR, Conover CA, Attar RM et al. 2006 In vitro and in vivo antitumor effects of the dual insulin-like growth factor-I/insulin receptor inhibitor, BMS-554417. Cancer research 66 362-371. (doi:10.1158/0008-5472.CAN-05-1107)

Han L, Ma Q, Li J, Liu H, Li W, Ma G, Xu Q, Zhou S \& Wu E 2011 High glucose promotes pancreatic cancer cell proliferation via the induction of EGF expression and transactivation of EGFR. PLOS ONE 6 e27074. (doi:10.1371/journal.pone.0027074)
Hardt PD, Kloer HU, Brendel MD \& Bretzel RG 2008 Is pancreatic (Type 3c) diabetes underdiagnosed and misdiagnosed? Diabetes Care 31 (suppl 2) S165-S169. (doi:10.2337/dc08-s244)

Hernandez-Diaz S \& Adami HO 2010 Diabetes therapy and cancer risk: causal effects and other plausible explanations. Diabetologia 53 802-808. (doi:10.1007/s00125010-1675-2)

Home PD \& Lagarenne P 2009 Combined randomized control trial experience of malignancies in studies using insulin glargine. Diabetologia 52 2499-2506. (doi:10.1007/s00125-009-1530-5)

Huang H, Dong X, Kang MX, Xu B, Chen Y, Zhang B, Chen J, Xie QP \& Wu YL 2010 Novel blood biomarkers of pancreatic cancer-associated diabetes mellitus identified by peripheral blood-based gene expression profiles. American Journal of Gastroenterology 105 1661-1669. (doi:10.1038/ajg.2010.32)

Huxley R, Ansary-Moghaddam A, Berrington de González A, Barzi F \& Woodward M 2005 Type-II diabetes and pancreatic cancer: a meta-analysis of 36 studies. British Journal of Cancer 92 2076-2083. (doi:10.1038/sj.bjc. 6602619)

Jee SH, Ohrr H, Sull JW, Yun JE, Ji M \& Samet JM 2005 Fasting serum glucose level and cancer risk in Korean men and women. Journal of the American Medical Association 293 194-202. (doi:10.1001/jama.293.2.194)

Jemal A, Siegel R, Xu J \& Ward E 2010 Cancer statistics, 2010. CA: A Cancer Journal for Clinicians 60 277-300. (doi:10.3322/caac.20073)

Jemal A, Bray F, Center MM, Ferlay J, Ward E \& Forman D 2011 Global cancer statistics. CA: A Cancer Journal for Clinicians 61 69-90. (doi:10.3322/caac.20107)

Jiao L, Berrington de Gonzalez A, Hartge P, Pfeiffer RM, Park Y, Freedman DM, Gail MH, Alavanja MC, Albanes D, Beane Freeman LE et al. 2010 Body mass index, effect modifiers, and risk of pancreatic cancer: a pooled study of seven prospective cohorts. Cancer Causes \& Control 21 1305-1314. (doi:10.1007/s10552-010-9558-x)

Jiralerspong S, Palla SL, Giordano SH, Meric-Bernstam F, Liedtke C, Barnett CM, Hsu L, Hung MC, Hortobagyi GN \& Gonzalez-Angulo AM 2009 Metformin and pathologic complete responses to neoadjuvant chemotherapy in diabetic patients with breast cancer. Journal of Clinical Oncology 27 3297-3302. (doi:10.1200/JCO.2009.19. 6410)

Johansen D, Stocks T, Jonsson H, Lindkvist B, Björge T, Concin H, Almquist M, Häggström C, Engeland A, Ulmer H et al. 2010 Metabolic factors and the risk of pancreatic cancer: a prospective analysis of almost 580,000 men and women in the Metabolic Syndrome and Cancer Project. Cancer Epidemiology, Biomarkers \& Prevention 19 2307-2317. (doi:10.1158/1055-9965.EPI-10-0234)

Johnson JA, Bowker SL, Richardson K \& Marra CA 2011 Time-varying incidence of cancer after the onset of type 2 diabetes: evidence of potential detection bias. Diabetologia 54 2263-2271. (doi:10.1007/s00125-011-2242-1) 
Jonasson JM, Ljung R, Talback M, Haglund B, Gudbjornsdottir S \& Steineck G 2009 Insulin glargine use and short-term incidence of malignancies a population-based follow-up study in Sweden. Diabetologia 52 1745-1754. (doi:10.1007/s00125009-1444-2)

Knowler WC, Barrett-Connor E, Fowler SE, Hamman RF, Lachin JM, Walker EA \& Nathan DM 2002 Diabetes program prevention research group. Reduction in the incidence of type 2 diabetes with lifestyle intervention or metformin. New England Journal of Medicine 346 393-403. (doi:10.1056/NEJMoa012512)

Ko AH \& Tempero MA 2009 Personalized medicine for pancreatic cancer: a step in the right direction. Gastroenterology 136 43-45. (doi:10.1053/j.gastro.2008. 11.027)

Koizumi M, Doi R, Toyoda E, Masui T, Tulachan SS, Kawaguchi Y, Fujimoto K, Gittes GK \& Imamura M 2003 Increased PDX-1 expression is associated with outcome in patients with pancreatic cancer. Surgery 134 260-266. (doi:10.1067/msy.2003.231)

Kornmann M, Maruyama H, Bergmann U, Tangvoranuntakul P, Beger HG, White MF \& Korc M 1998 Enhanced expression of the insulin receptor substrate-2 docking protein in human pancreatic cancer. Cancer Research $\mathbf{5 8}$ 4250-4254.

Lacy MQ, Alsina M, Fonseca R, Paccagnella ML, Melvin CL, Yin D, Sharma A, Enriquez Sarano M, Pollak M, Jagannath S et al. 2008 Phase I, pharmacokinetic and pharmacodynamic study of the anti-insulin like growth factor type 1 Receptor monoclonal antibody CP-751,871 in patients with multiple myeloma. Journal of Clinical Oncology 26 3196-3203. (doi:10.1200/JCO.2007.15. 9319)

Lee JH, Kim SA, Park HY, Lee KH, Lee KT, Lee JK, Bae JC \& Kim KW 2011 $a$ New-onset diabetes patients need pancreatic cancer screening? Journal of Clinical Gastroenterology 46 e58-e61. (doi:10.1097/MCG. 0b013e318238348c)

Lee MS, Hsu CC, Wahlqvist M, Tsai HN, Chang YH \& Huang YC $2011 b$ Type 2 diabetes increases and metformin reduces total, colorectal, liver, and pancreatic incidences in Taiwanese: a representative population prospective cohort study of 800,000 individuals. $B M C$ Cancer 11 20. (doi:10.1186/1471-2407-11-20)

Li D 2012 Diabetes and pancreatic cancer. Molecular Carcinogenesis 51 64-74. (doi:10.1002/mc.20771)

Li D, Yeung SC, Hassan MM, Konopleva M \& Abbruzzese JL 2009 Antidiabetic therapies affect risk of pancreatic cancer. Gastroenterology 137 482-488. (doi:10.1053/j.gastro.2009.04.013)

Li D, Tang H, Hassan M, Holly EA, Bracci PM \& Silverman DT 2011 Diabetes and risk of pancreatic cancer: a pooled analysis of three large case-control studies. Cancer Causes \& Control 22 189-197. (doi:10.1007/s10552-010-9686-3)
Liao KF, Lai SW, Li CI \& Chen WC 2012 Diabetes mellitus correlates with increased risk of pancreatic cancer: a population-based cohort study in Taiwan. Journal of Gastroenterology and Hepatology 27 709-713. (doi:10.1111/j.1440-1746.2011.06938.x)

Libby G, Donnelly LA, Donnan PT, Alessi DR, Morris AD \& Evans JM 2009 New users of metformin are at low risk of incident cancer: a cohort study among people with type 2 diabetes. Diabetes Care 32 1620-1625. (doi:10.2337/ dc08-2175)

Liu J, Knezetic JA, Strommer L, Permert J, Larsson J \& Adrian TE 2000 The intracellular mechanism of insulin resistance in pancreatic cancer patients. Journal of Clinical Endocrinology and Metabolism 85 1232-1238. (doi:10.1210/jc.85.3.1232)

Liu SH, Patel S, Gingras MC, Nemumaitis J, Zhou G, Chen C, Fisher W, Gibbs R \& Brunicardi FC 2011 PDX-1 demonstration of oncogenic properties in pancreatic cancer. Cancer 117 723-733. (doi:10.1002/cncr.25629)

Loser C, Mollgaard A \& Folsch UR 1996 Faecal elastase-1: a novel, highly sensitive, and specific tubeless pancreatic function test. Gut 39 580-586. (doi:10.1136/ gut.39.4.580)

Lowenfels AB, Maisonneuve P, Cavallini G, Ammann RW, Lankisch PG, Andersen JR, Dimagno EP, Andrén-Sandberg A \& Domellöf L 1993 Pancreatitis and the risk of pancreatic cancer. International Pancreatitis Study Group. New England Journal of Medicine 328 1433-1437. (doi:10.1056/ NEJM199305203282001)

Magruder JT, Elahi D \& Andersen DK 2011 Diabetes and pancreatic cancer: chicken or egg? Pancreas 40 339-351. (doi:10.1097/MPA.0b013e318209e05d)

Maisonneuve P, Lowenfels AB, Bueno-de-Mesquita HB, Ghadirian P, Baghurst PA, Zatonski WA, Miller AB, Duell EJ, Boffetta P \& Boyle P 2010 Past medical history and pancreatic cancer risk: results from a multicenter case-control study. Annals of Epidemiology 20 92-98. (doi:10.1016/j.annepidem.2009.11.010)

Malizzia LJ \& Hsu A 2008 Temsirolimus, an mTOR inhibitor for treatment of patients with advanced renal cell carcinoma. Clinical Journal of Oncology Nursing 12 639-646. (doi:10.1188/08.CJON.639-646)

Malka D, Hammel P, Sauvanet A, Rufat P, O'Toole D, Bardet P, Belghiti J, Bernades P, Ruszniewski P \& Lévy P 2000 Risk factors for diabetes mellitus in chronic pancreatitis. Gastroenterology 119 1324-1332. (doi:10.1053/gast.2000.19286)

Matveyenko AV, Dry S, Cox HI, Moshtaghian A, Gurlo T, Galasso R, Butler AE \& Butler PC 2009 Beneficial endocrine but adverse exocrine effects of sitagliptin in the human islet amyloid polypeptide transgenic rat model of type 2 diabetes: interactions with metformin. Diabetes 58 1604-1615. (doi:10.2337/db09-0058)

Michaud DS, Giovannucci E, Willett WC, Colditz GA, Stampfer MJ \& Fuchs CS 2001 Physical activity, obesity, 
height, and the risk of pancreatic cancer. Journal of the American Medical Association 286 921-929. (doi:10.1001/jama.286.8.921)

Monami M, Lamanna C, Balzi D, Marchionni N \& Mannucci E 2009 Sulfonylureas and cancer: a case-control study. Acta Diabetologica 46 279-284. (doi:10.1007/s00592-008-0083-2)

Nathan DM, Holman RR, Buse JB, Sherwin R, Davidson MB, Zinman B \& Ferrannini E 2009 Medical management of hyperglycemia in type 2 diabetes: a consensus algorithm for the initiation and adjustment of therapy. A consensus statement by the American Diabetes Association and the European Association for the Study of Diabetes. Diabetes Care 32 193-203. (doi:10.2337/dc08-9025)

Ogawa Y, Tanaka M, Inoue K, Yamaguchi K, Chijiiwa K, Mizumoto K, Tsutsu N \& Nakamura Y 2002 A prospective pancreatographic study of the prevalence of pancreatic carcinoma in patients with diabetes mellitus. Cancer 94 2344-2349. (doi:10.1002/cncr.10493)

Pannala R, Leirness JB, Bamlet WR, Basu A, Petersen GM \& Chari ST 2008 Prevalence and clinical profile of pancreatic cancer-associated diabetes mellitus. Gastroenterology 134 981-987. (doi:10.1053/j.gastro. 2008.01.039)

Pannala R, Basu A, Petersen GM \& Chari ST 2009 New-onset diabetes: a potential clue to the early diagnosis of pancreatic cancer. Lancet Oncology 10 88-95. (doi:10.1016/S1470-2045(08)70337-1)

Perfetti R, Zhou J, Doyle ME \& Egan JM 2000 Glucagon-like peptide- 1 induces cell proliferation and pancreaticduodenum homeobox-1 expression and increases endocrine cell mass in the pancreas of old, glucose intolerant rats. Endocrinology 141 4600-4605. (doi:10.1210/en. 141.12.4600)

Permert J, Ihse I, Jorfeldt L, von Schenck H, Arnquist HJ \& Larsson J 1993 Improved glucose metabolism after subtotal pancreatectomy for pancreatic cancer. British Journal of Surgery 80 1047-1050. (doi:10.1002/bjs. 1800800841)

Permert J, Larsson J, Westermark GT, Herrington MK, Christmanson L, Pour PM, Westermark P \& Adrian TE 1994 Islet amyloid polypeptide in patients with pancreatic cancer and diabetes. New England Journal of Medicine 330 313-318. (doi:10.1056/ NEJM199402033300503)

Permert J, Herrington M, Kazakoff K, Pour PM \& Adrian TE 2001 Early changes in islet hormone secretion in the hamster pancreatic cancer model. Teratogenesis, Carcinogenesis, and Mutagenesis 21 59-67. (doi:10.1002/1520-6866(2001)21:1 < 59::AID-TCM6> 3.0.CO;2-V)

Petersen GM, Amundadottir L, Fuchs CS, Kraft P, Stolzenberg-Solomon RZ, Jacobs KB, Arslan AA, Bueno-de-Mesquita HB, Gallinger S, Gross M et al. 2010 A genome-wide association study identifies pancreatic cancer susceptibility loci on chromosomes $13 \mathrm{q} 22.1$, 1q32.1 and 5p15.33. Nature Genetics 42 224-228. (doi:10.1038/ng.522)

Pfeffer F, Koczan D, Adam U, Benz S, von Dobschuetz E, Prall F, Nizze H, Thiesen HJ, Hopt U \& Lobler M 2004 Expression of connexin 26 in islets of Langerhans is associated with impaired glucose tolerance in patients with pancreatic carcinoma. Pancreas 29 284-290. (doi:10.1097/00006676-200411000-00007)

Pierce BL, Austin MA \& Ahsan H 2011 Association study of type 2 diabetes genetic susceptibility variants and risk of pancreatic cancer: an analysis of PanScan-I data. Cancer Causes \& Control 22 877-883. (doi:10.1007/s10552-0119760-5)

Pollak M 2008 Insulin and insulin-like growth factor signalling in neoplasia. Nature Reviews. Cancer $\mathbf{8}$ 915-928. (doi:10.1038/nrc2536)

Prizment AE, Gross M, Rasmussen-Torvik L, Peacock JM \& Anderson KE 2012 Genes related to diabetes may be associated with pancreatic cancer in a population-based case-control study in Minnesota. Pancreas 41 50-53. (doi:10.1097/MPA.0b013e3182247625)

del Rincon JP, Iida K, Gaylinn BD, McCurdy CE, Leitner JW, Barbour LA, Kopchick JJ, Friedman JE, Draznin B \& Thorner MO 2007 Growth hormone regulation of p85alpha expression and phosphoinositide 3-kinase activity in adipose tissue: mechanism for growth hormone mediated insulin resistance. Diabetes 56 1638-1646. (doi:10.2337/db06-0299)

Rothenbacher D, Löw M, Hardt PD, Klör HU, Ziegler H \& Brenner H 2005 Prevalence and determinants of exocrine pancreatitic insufficiency among older adults: results of a population-based study. Scandinavian Journal of Gasteroenterology 40 697-704. (doi:10.1080/ 00365520510023116)

Rozengurt E, Sinnett-Smith J \& Kisfalvi K 2010 Crosstalk between insulin/insulin-like growth factor-1 receptors and $\mathrm{G}$ protein-coupled receptor signaling systems: a novel target for the antidiabetic drug metformin in pancreatic cancer. Clinical Cancer Research: an Official Journal of the American Association for Cancer Research 16 2505-2511. (doi:10.1158/1078-0432.CCR09-2229)

Sadeghi N, Abbruzzese JL, Yeung SJ, Hassan M \& Li D 2011 Effect of metformin on survival of diabetic patients with pancreatic adenocarcinoma. Journal of Clinical Oncology 29 (May 20 Supplement) 4063.

Saylor PJ \& Smith MR 2009 Metabolic complications of androgen deprivation therapy for prostate cancer. Journal of Urology 181 1998-2006. (doi:10.1016/j.juro. 2009.01.047)

Schneider MB, Matsuzaki H, Haorah J, Ulrich A, Standop J, Ding XZ, Adrian TE \& Pour PM 2001 Prevention of pancreatic cancer induction in hamsters by metformin. Gastroenterology 120 1263-1270. (doi:10.1053/gast. 2001.23258) 
Siegel R, Naishadham D \& Jemal A 2012 Cancer statistics, 2012. CA: A Cancer Journal for Clinicians 62 10-29. (doi:10.3322/caac.20138)

Silverman DT 2001 Risk factors for pancreatic cancer: a case-control study based on direct interviews.

Teratogenesis, Carcinogenesis, and Mutagenesis 21 7-25. (doi:10.1002/1520-6866(2001)21:1<7::AIDTCM3 > 3.0.CO;2-A)

Sjöström L, Narbro K, Sjöström CD, Karason K, Larsson B, Wedel H, Lystig T, Sullivan M, Bouchard C, Carlsson B et al. 2007 Effects of bariatric surgery on mortality in Swedish obese subjects. New England Journal of Medicine 357 741-752. (doi:10.1056/NEJMoa066254)

Slezak LA \& Andersen DK 2001 Pancreatic resection: effects on glucose metabolism. World Journal of Surgery 25 452-460. (doi:10.1007/s002680020337)

Stevens RJ, Roddam AW \& Beral V 2007 Pancreatic cancer in type 1 and young-onset diabetes: systematic review and meta-analysis. British Journal of Cancer 96 507-509. (doi:10.1038/sj.bjc.6603571)

Stoffers DA, Kieffer TJ, Hussain MA, Drucker DJ, BonnerWeir S, Habeber JF \& Egan JM 2000 Insulinotropic glucagon-like peptide-1 agonists stimulate expression of homeodomain protein IDX-1 and increase islet size in mouse pancreas. Diabetes 49 741-748. (doi:10.2337/ diabetes.49.5.741)

Stolzenberg-Solomon RZ, Graubard BI, Chari S, Limburg P, Taylor PR, Virtamo J \& Albanes D 2005 Insulin, glucose, insulin resistance and pancreatic cancer in male smokers. Journal of the American Medical Association 294 2872-2878. (doi:10.1001/jama.294.22.2872)

Teucher B, Rohrmann S \& Kaaks R 2010 Obesity: focus on all-cause mortality and cancer. Maturitas 65 112-116. (doi:10.1016/j.maturitas.2009.11.018)
Van Kruijsdijk RC, van der Wall E \& Visseren FL 2009 Obesity and cancer: the role of dysfunctional adipose tissue. Cancer Epidemiology, Biomarkers \& Prevention 18 2569-2578. (doi:10.1158/1055-9965.EPI09-0372)

Wang XP, Li ZJ, Magnusson J \& Brunicardi FC 2005 Tissue microarray analysis of pancreatic duodenal homeobox-1 in human cancers. World Journal of Surgery 29 334-338. (doi:10.1007/s00268-004-7823-4)

Wideroff L, Gridley G, Mellemkjaer L, Chow WH, Linet M, Keehn S, Borch-Johnsen K \& Olsen JH 1997 Cancer incidence in a population-based cohort of patients hospitalized with diabetes mellitus in Denmark. Journal of the National Cancer Institute 89 1360-1365. (doi:10.1093/jnci/89.18.1360)

Yacoub A, Siegel E \& Makhoul E 2011 Pancreatic cancer and diabetes mellitus: a retrospective cohort study. Journal of Clinical Oncology 29 (Suppl) 4102.

Zendehdel K, Nyren O, Ostenson CG, Adami HO, Ekbom A \& Ye W 2003 Cancer incidence in patients with type 1 diabetes mellitus: a population-based cohort study in Sweden. Journal of the National Cancer Institute 95 1797-1800. (doi:10.1093/jnci/djg105)

Zhang ZJ, Cui W, Zheng ZJ, Zhao G, Kan H, Kip KE \& Song Y 2011 Reduced risk of colorectal cancer with metformin therapy in patients with type 2 diabetes. Diabetes Care 34 2323-2328. (doi:10.2337/dc11-0512)

Received in final form 27 June 2012

Accepted 26 July 2012

Made available online as an Accepted Preprint 27 July 2012 